\title{
FaPOD27 functions in the metabolism of polyphenols in strawberry fruit (Fragaria sp.)
}

\section{Su-Ying Yeh, Fong-Chin Huang, Thomas Hoffmann, Mechthild Mayershofer and Wilfried Schwab*}

Biotechnology of Natural Products, WZW - TUM School of Life Sciences Weihenstephan, Technische Universität München, Freising, Germany

\section{Edited by:}

Stefan Martens, Edmund Mach

Foundation, Italy

Reviewed by:

Akifumi Sugiyama, Kyoto University, Japan

Carlos Sanz, Spanish National

Research Council, Spain

*Correspondence:

Wilfried Schwab, Biotechnology of

Natural Products, Technische

Universität München,

Liesel-Beckmann-Str. 1,

85354 Freising, Germany

e-mail:wilfried.schwab@tum.de
The strawberry (Fragaria $\times$ ananassa) is one of the most preferred fresh fruit worldwide, accumulates numerous flavonoids but has limited shelf life due to excessive tissue softening caused by cell wall degradation. Since lignin is one of the polymers that strengthen plant cell walls and might contribute to some extent to fruit firmness monolignol biosynthesis was studied in strawberry fruit. Cinnamoyl-CoA reductase (CCR), cinnamyl alcohol dehydrogenase (CAD), and a peroxidase (POD27) gene were strongly expressed in red, ripe fruit whereas a second $P O D$ gene was primarily expressed in green, immature fruit. Moreover, FaPOD27 transcripts were strongly and constitutively induced in fruits exposed to Agrobacterium infection. Gene expression levels and enzymatic activities of FaCCR and FaCAD were efficiently suppressed through RNAi in FaCCR- and FaCAD-silenced strawberries. Besides, significantly elevated FaPOD transcript levels were detected after agroinfiltration of $\mathrm{pBI}-\mathrm{FaPOD}$ constructs in fruits. At the same time, levels of G-monomers were considerably reduced in FaCCR-silenced fruits whereas the proportion of both G- and S-monomers decisively decreased in FaCAD-silenced and $\mathrm{pBI}-\mathrm{FaPOD}$ fruits. Development, firmness, and lignin level of the treated fruits were similar to $\mathrm{pBI}$-intron control fruits, presumably attributed to increased expression levels of FaPOD27 upon agroinfiltration. Additionally, enhanced firmness, accompanied with elevated lignin levels, was revealed in chalcone synthase-deficient fruits $\left(\mathrm{CHS}^{-}\right)$, independent of down- or up-regulation of individual and combined FaCCR, FaCAD, and FaPOD genes by agroinfiltration, when compared to $\mathrm{CHS}^{-} / \mathrm{pBI}$-intron control fruits. These approaches provide further insight into the genetic control of flavonoid and lignin synthesis in strawberries. The results suggest that FaPOD27 is a key gene for lignin biosynthesis in strawberry fruit and thus to improving the firmness of strawberries.

Keywords: strawberry, lignification, peroxidase, fruit firmness, monolignol genes

\section{INTRODUCTION}

The strawberry (Fragaria $\times$ ananassa) is a highly perishable fruit, with a short shelf life due to increased cell wall degradation during the late stages of ripening, which results in soft fruits (Lefever et al., 2004). Thus, fruit texture plays an important role as a quality marker for consumers and food processing companies since fruit softening renders the fruit palatable but facilitates pathogen infection and accelerates fruit postharvest decay. Consequently, fruit firmness is an important target for genetic engineering to improve the quality of strawberries and to prolong the shelf-life of fresh fruit in markets (Chapple and Carpita, 1998; Manning, 1998).

As fruit softening is associated with cell wall disassembly (Seymour and Gross, 1996) several studies aimed at slowing down this degradation process to improve the texture of strawberries. The pectate lyase gene is highly expressed during strawberry fruit ripening and is considered to play an important role in pectin decomposition (Dominguez-Puigjaner et al., 1997; MedinaEscobar et al., 1997). Transgenic strawberry fruits harboring antisense pectate lyase genes resulted in reduced pectate lyase activity, as well as increased fruit firmness (Jiménez-Bermúdez et al., 2002; Quesada et al., 2009).

To identify candidate genes which might be associated with textural differences in Fragaria accessions, gene expression levels were compared for a soft and a firm cultivar (Salentijn et al., 2003). Although putative cell wall related genes displayed differential expression, two genes of the lignin biosynthesis pathway namely cinnamoyl-CoA reductase $(C C R)$ and cinnamyl alcohol dehydrogenase $(C A D)$ showed the highest difference in expression level. The CCR gene showed higher expression levels in varieties that produce fruits with soft tissue, while $C A D$ showed higher levels in the varieties with firm fruit tissue (Salentijn et al., 2003). Similarly, in loquat fruit (Eriobotrya japonica Lindl.), an increase in fruit firmness is associated with lignification of plant tissue and with activities of CAD and peroxidase (POD) enzymes that are involved in lignin biosynthesis (Boerjan et al., 2003; Cai et al., 2006). CCR (EC 1.2.1.44) is the first committed enzyme of the lignin branch biosynthetic pathway, and it mainly reduces cinnamoyl-CoA esters to yield corresponding aldehydes (Sarni et al., 1984). CCR has been considered to be a potential 
control point in regulating carbon flux toward lignin production (Lacombe et al., 1997). CAD (EC 1.1.1.195) catalyzes the conversion of cinnamyl aldehydes to their corresponding monolignols that are precursors for lignin polymerization in cell walls (Sarni et al., 1984) whereas POD (EC1.11.1.7) is responsible for the polymerization of monolignols via radical-radical coupling reactions (Almagro et al., 2009).

Lignin is derived from oxidative polymerization of three different monolignols ( $p$-coumaryl, coniferyl and sinapyl alcohol) referred to as $p$-hydroxyphenyl $(\mathrm{H})$, guaiacyl $(\mathrm{G})$, and syringyl (S) lignin, respectively. However, due to the generally broad substrate tolerance of POD enzymes various substrates such as monolignols, ferulic acids, hydroxycinnamyl aldehydes, and acylated monolignols, can be incorporated into the branched lignin (Passardi et al., 2004b; Hayashi, 2006; Ralph et al., 2008; Weng and Chapple, 2010). PODs produce phenoxy radicals that form linkages (diphenolic) between cell wall polymers, causing crosslink formation and stiffening of the cell wall (Passardi et al., 2004a). Thus, lignin may functions as mechanical support for plant organs, in defense against pathogenic attacks, and in water transport in vascular plants (Dixon, 2001; Boerjan et al., 2003).

Angiosperm lignin mainly contains both $\mathrm{G}$ and $\mathrm{S}$ units, and a low content of $\mathrm{H}$ units. A difference in lignin composition is reflected in the substrate specificity of enzymes or the regulated differential carbon flow into the synthesis of various lignin precursors in lignin biosynthesis. Indeed, lignin represents a carbon sink in higher plants. $p$-Coumaroyl-CoA is situated at the branching point of the metabolic routes leading to either flavonoid or monolignol biosynthetic pathways, as it is the common substrate of chalcone synthase (CHS), hydroxycinnamoyl transferase (HCT), and CCR enzymes (Figure 1; Boerjan et al., 2003; Besseau et al., 2007). When the carbon flow down the flavonoid pathway becomes limited, $p$-coumaroyl-CoA provides increased levels of monolignols (Lunkenbein et al., 2006).

The monomeric units in lignin are linked together through at least six different types of bonding, with the $\beta$-O- 4 ( $\beta$-aryl ether) group being the most frequent linkage (Boerjan et al., 2003; Weng and Chapple, 2010). Lignin production and lignification of plants is mostly accompanied by an increase in the activity of PODs when plants are responding to environmental stimuli, such as wounding and pathogen attacks (Chittoor et al., 1997; Passardi et al., 2006). To resist various stresses, plants may modify lignin content and/or lignin composition in the plant body (Bonello and Blodgett, 2003; Moura et al., 2010). Lignin induction occurs in the infected plants, in which a mechanical barrier might diminish the probability of pathogen invasion.

Lignin production is mediated by the coordinated expression of several enzymes in the monolignol pathway (Boerjan et al., 2003; Weng and Chapple, 2010). CCR, CAD, and POD genes have been cloned and characterized from plant model species such as Arabidopsis and poplar (Lauvergeat et al., 2001; Li et al., 2001; Welinder et al., 2002; Kim et al., 2004) and functional studies have been carried out by evaluating stable transgenic plants (Whetten et al., 1998; Anterola and Lewis, 2002). Down- and up-regulation



FIGURE 1 | Flavonoid and monolignol biosynthetic pathways. PAL, phenylalanine ammonia lyase; $4 \mathrm{CL}$, 4-coumaroyl-CoA ligase; $\mathrm{CHS}$, chalcone synthase; HCT, hydroxycinnamoyl transferase; CCR, cinnamoyl-CoA reductase; CAD, cinnamyl alcohol dehydrogenase; POD, peroxidase. Arrow

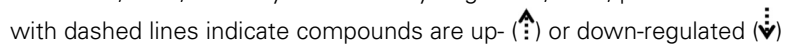

when fruits were agroinfiltrated pBI-intron (control constructs), down- or up-regulation of individual genes ( $F a C C R, F a C A D$, or FaPOD) (Fig. S12). The green shade indicating $p$-coumaroyl-COA is the common substrate of $\mathrm{CHS}$, $\mathrm{HCT}$, and CCR. Red CCR, CAD, and POD indicate down- and up-regulated genes. 
of $\mathrm{FaCCR}, \mathrm{FaCAD}$, and $\mathrm{FaPOD}$ gene expression in strawberry fruit have not been reported, yet.

Only recently, examination of the transcriptome, coupled with metabolite profiling analysis of different commercial $F . x$ ananassa varieties revealed FaPOD27 (FaPRX27) as a gene associated with lignin biosynthesis and firmness in strawberry fruit (Ring et al., 2013). Since lignin-related genes have also been detected as differentially expressed in firm fruits in comparison to soft fruits (Salentijn et al., 2003) we investigated lignin formation and composition and its contribution to firmness in strawberry fruit. Lignin biosynthesis genes were isolated from F. $x$ ananassa and functionally characterized by biochemical analyses of the encoded proteins as well as by reverse genetics approaches involving agroinfiltration of RNAi and overexpression constructs. Agroinfiltration of strawberries provides an easy and rapid approach to study gene functions (Hoffmann et al., 2006; Schwab et al., 2011).

\section{MATERIALS AND METHODS PLANT MATERIALS AND CHEMICALS}

Fragaria $\times$ ananassa $\mathrm{cv}$. Elsanta and transgenic strawberry plants with an antisense CHS gene $(F . \times$ ananassa cv. Calypso; Lunkenbein et al., 2006; $\mathrm{CHS}^{-}$) were maintained under greenhouse conditions $(16 / 8 \mathrm{~h}$, light/dark period). All chemicals, solvents, and reference compounds were purchased from SigmaAldrich (Munich, Germany), Fluka (Munich, Germany), Merck (Darmstadt, Germany), Roth (Karlsruhe, Germany), or Baker (Austin, TX, USA) unless otherwise stated.

\section{GENE CLONING}

Total RNA of ripe fruit was extracted as described (Liao et al., 2004). cDNAs as PCR templates were obtained by reverse transcription M-MLV RT H(-) (Promega, Mannheim, Germany) using a random hexamer primer. In order to amplify alleles of the FaCCR or FaCAD genes, degenerated primers were designed based on deduced amino acid sequences of CCR and $C A D$ in the GenBank database (www.ncbi.nlm.nih.gov). Since the $\mathrm{N}$ - or C-terminal ends of the deduced amino acid sequences of $P O D$ genes from different species (Welinder et al., 2002; Passardi et al., 2004a) are highly variable, specific primers of FaPOD were designed based on the full-length coding sequence of POD (Fragaria vesca) obtained from the Fragaria Vesca Genome Browser database (https://strawberry.plantandfood.co.nz/index. html). The isolation of a full-length coding region sequence of $F a C C R, F a C A D$, and $F a P O D$ was performed by PCR using a high-fidelity $P f u$ DNA polymerase and its degenerated or specific primers (Table S1). Positive clones were identified by sequencing. FaPOD27 was isolated as described (Ring et al., 2013).

\section{CONSTRUCTION OF HETEROLOGOUS EXPRESSION PLASMIDS}

After sequencing confirmation, PCR fragments of FaCCR and FaPOD were amplified by PCR using designed primers (Table $\mathrm{S} 1$ ), based on the full-length coding region, with restriction sites. PCR fragments of the FaCCR and FaPOD cut with BamHI and SmaI were subcloned into a BamHI-SmaI cut pGEX-4T-1 vector (GE Healthcare, Munich, Germany), in frame with a coding region for an N-terminal GST (glutathione S-transferase) tag. In addition, the full-length coding region of $F a C A D$ was constructed in pET-29a(+) (Novagen, Darmstadt, Germany) as PCR template DNA. The amplified PCR products of $F a C A D$ cut with $B a m \mathrm{HI}$ and $\mathrm{XbaI}$ were subcloned into a BamHI-XbaI cut pYES2 vector (Invitrogen). The resulting plasmid was GST-FaCCR, GSTFaPOD, and pYES2-CAD, respectively. Additionally, the resulting plasmid GST-FaPOD27 was provided by Ring et al. (2013). The full-length coding region sequences of FaCCR (accession no. JX290510), FaCAD (accession no. JX290511), FaPOD (accession no. JX290512), FaPOD27 (accession no. JX290513) were submitted to the GenBank database.

\section{CONSTRUCTION OF ihPRNA AND OVEREXPRESSION PLASMIDS}

To prepare vectors for intron-hairpin RNA-mediated gene silencing, PCR products of $F a C C R, F a C A D$, or $F a P O D$ were amplified by PCR using primers (Table S1) and a high-fidelity Phusion DNA polymerase to introduce NheI and SpeI sites with bluntend PCR fragments. Then, a 300-bp PCR fragment was digested with SpeI and cloned into the compatible site of a SpeI-Ecl136II pSKAscI35SIntTER vector containing one intron (AY158836, nucleotides 4886-4993) to produce an intermediate pSKAscIA. Afterwards, the same PCR products were additionally digested with NheI and SpeI and cloned into a compatible XbaI site of the pSKAscIA vector to produce a pSKAscIAS vector. Finally, the sense- and antisense-mediated fragments were cut AscI from the pSKAscIAS vector and then cloned into the same sites of a binary $\mathrm{pBIAscI}$ vector to produce the resulting plasmid $\mathrm{pBI}-\mathrm{FaCCR}$, $\mathrm{pBI}-\mathrm{FaCAD} i$, and $\mathrm{pBI}-\mathrm{FaPOD} i$. In addition to construct overexpression vectors, a full-length coding sequence of $F a C C R, F a C A D$, or FaPOD was amplified by PCR using the Phusion DNA polymerase and primers (Table S1). PCR fragments cut by Bam HI and SmaI were cloned into the same sites of the binary vector $\mathrm{pBI} 121$ to produce the resulting plasmid $\mathrm{pBI}-F a C C R$, $\mathrm{pBI}-F a C A D$, and pBI-FaPOD.

\section{HETEROLOGOUS PROTEIN EXPRESSION AND PROTEIN PURIFICATION}

A bacterial culture E. coli BL21 (DE3) pLysS (Novagen, Darmstadt, Germany) containing GST-FaCCR or GST (control) was grown in $\mathrm{LB}$ with appropriate antibiotics at $37^{\circ} \mathrm{C}$, with shaking at $150 \mathrm{rpm}$. When $\mathrm{OD}_{600}$ reached $0.5-0.6$, IPTG was added to a final concentration of $0.2 \mathrm{mM}$ to the bacterial culture at $16^{\circ} \mathrm{C}$, with shaking at $150 \mathrm{rpm}$ for $16-18 \mathrm{~h}$. GST-FaCCR was purified using the GST Bind resin (Novagen, Darmstadt, Germany) according to the manufacturer's instructions. In addition, the resulting plasmid GST-POD was transformed into E. coli Rosetta (DE3)pLysS cells (Novagen, Darmstadt, Germany). The recombinant protein was expressed and isolated as described (Ring et al., 2013). Besides, pYES2-FaCAD was transformed into yeast cells (S. cerevisae INVSc.1) using the $S$. c. EasyComp Transformation Kit (Invitrogen, Darmstadt, Germany). Positive clones were confirmed by PCR screen, and inoculated in a SC-U selective medium plus $2 \%$ galactose to express pYES2-FaCAD in yeast cells. Protein extraction was carried out according to the manufacturer's instructions. The supernatant was used for enzymatic assays. Expression and purification of FaPOD27 was performed as described (Ring et al., 2013). 


\section{BIOCHEMICAL CHARACTERIZATION OF GST-FaCCR}

Kinetic parameters were determined spectrophotometrically according to Wengenmayer et al. (1976). The substrates (cinnamoyl-, p-coumaroyl-, caffeoyl-, and feruloyl-CoA) were enzymatically synthesized as described by Beuerle and Pichersky (2002). To determine $\mathrm{pH}$ and temperature optimum, FaCCR activity using feruloyl-CoA as substrate was measured spectrophotometrically and by LC-UV-ESI-MS ${ }^{\mathrm{n}}$ analysis, respectively.

\section{IDENTIFICATION OF REACTION PRODUCTS BY LC-UV-ESI-MS}

To verify the identity of reaction products, a FaCCR reaction mixture consisting of $100 \mathrm{mM}$ sodium phosphate ( $\mathrm{pH}$ 6), $0.1 \mathrm{mM}$ of $\mathrm{NADPH}, 70 \mu \mathrm{M}$ of hydroxycinnamoyl-CoA, and $2 \mu \mathrm{g}$ of purified GST-FaCCR was incubated at $25^{\circ} \mathrm{C}$ for $20 \mathrm{~min}$. The reaction was stopped by the addition of $25 \mu \mathrm{l}$ of acetic acid. Following centrifugation at top speed for $10 \mathrm{~min}$, the clear supernatant was analyzed by LC-UV-ESI-MS ${ }^{n}$. In addition, a pYES2-CAD reaction mixture containing $100 \mathrm{mM}$ of sodium phosphate ( $\mathrm{pH} 6.5$ ), $200 \mu \mathrm{M}$ of NADPH, $100 \mu \mathrm{M}$ of coniferaldehyde, and 10-100 $\mu \mathrm{g}$ of crude protein was incubated at $30^{\circ} \mathrm{C}$ for $30 \mathrm{~min}$. The reaction mixture was extracted twice with an equal volume of ethyl acetate by vortexing for $30 \mathrm{~s}$. After centrifugation at top speed for $1 \mathrm{~min}$, ethyl acetate extracts were dried by Speed-Vac (ThermoScientific, Dreieich, Germany). For FaPOD and FaPOD27, $300 \mu \mathrm{l}$ of the reaction mixture, that included $50 \mathrm{mM}$ of sodium tartrate buffer ( $\mathrm{pH} 3.5), 50 \mu \mathrm{L}$ of substrate $(18 \mathrm{mM})$, and $50 \mu \mathrm{l}$ of crude proteins $(1.9 \mathrm{mg})$, was incubated at room temperature. $135 \mu \mathrm{M}$ of $\mathrm{H}_{2} \mathrm{O}_{2}$ (a $30 \%$ solution) was added to the mixture at 1-min intervals, one at a time for a total of $4 \mathrm{mM}$ of $\mathrm{H}_{2} \mathrm{O}_{2}$ (Ward et al., 2001). After $30 \mathrm{~min}$, the reaction mixture was extracted as described above. The dried samples were dissolved with $30 \mu \mathrm{l}$ of $50 \%$ methanol $(\mathrm{v} / \mathrm{v})$ and used directly for LC-UV-ESI-MS ${ }^{\mathrm{n}}$ analysis.

\section{cDNA SYNTHESIS AND qRT-PCR ANALYSIS}

Total RNA was treated with RNase-free DNase I (Fermentas, St. Leon-Rot, Germany) to remove the genomic DNA, according to the manufacturer's instructions. cDNA was synthesized from $1 \mu \mathrm{g}$ of DNase I-treated total RNA using the M-MLV RT H(-) and $1 \mu \mathrm{l}$ of $50 \mu \mathrm{M}$ random hexamer primer according to the manufacturer's instructions. Real-time polymerase chain reactions were performed in a 96-well reaction plate with a StepOnePlus ${ }^{\mathrm{TM}}$ realtime PCR system (Applied Biosystems, Darmstadt, Germany) using SYBR Green to monitor dscDNA synthesis. For all qRTPCR experiments, gene-specific primers (Table S2) were used for amplifications of target genes. An interspacer gene (Table S2) was used as an internal control for normalized expressing values. For data analysis of all samples, relative gene expression was quantified using the $2^{-\Delta \Delta C T}$ method (Livak and Schmittgen, 2001) to indicate fold changes of each sample related to the selected reference sample.

\section{GENE EXPRESSION STUDIES}

The differential expression of lignin biosynthetic genes (FaCCR, $F a C A D, F a P O D$, and FaPOD27) in vegetative tissues (leaves, roots, stems, and runners), flowers, and developed fruits at small green, green white, white, turning, and red stages was investigated. All samples were collected from $F . \times$ ananassa $\mathrm{cv}$. Elsanta and immediately frozen in liquid nitrogen as well as stored at $-80^{\circ} \mathrm{C}$ until used.

\section{WOUNDING AND PATHOGEN TREATMENTS}

To simulate wounding, a single fruit of $F . \times$ ananassa cv. Elsanta, at the turning stage, was infiltrated throughout the entire fruit with MMA medium (Hoffmann et al., 2006) by using a sterile 1-ml hypodermic syringe. Wounded and untreated control fruits were harvested at different times (12 min, 6, 12, 24, and $48 \mathrm{~h}$ ). In addition to simulate pathogen infection in a fruit, F. $x$ ananassa cv. Elsanta fruit in the turning stage was infiltrated throughout the entire fruit with a suspension of Agrobacterium AGL0. Samples were collected at different times (1,3,6, 12, 24, 48, and 96h). All treated fruits remained attached to the plant until harvested. Wild-type (untreated) fruits were used as controls and harvested at the same time. All samples were immediately frozen in liquid nitrogen and stored at $-80^{\circ} \mathrm{C}$.

\section{INFILTRATION OF FRUITS THROUGH AGROBACTERIUM}

All constructs were transferred into Agrobacterium AGLO strain (Lazo et al., 1991). Infiltration of strawberry fruit was carried as described (Hoffmann et al., 2006). To assess the effects of independent down-regulation and up-regulation of lignin biosynthetic genes on $F . \times$ ananassa cv. Elsanta and cv. Calypso $\left(\mathrm{CHS}^{-}\right)$ fruits, strawberry fruits of the white developmental stage were injected with Agrobacterium suspensions. Agrobacterium carrying a pBI-FaCCR $i$, pBI-FaCAD $i$, and pBI-FaPOD $i$ construct were used to down-regulate lignin genes whereas Agrobacterium suspensions carrying a pBI-FaCCR, pBI-FaCAD, and pBI-FaPOD construct were applied to up-regulate lignin genes. In addition, fruit of the white developmental stage was injected with a mixture of Agrobacterium harboring pBI-FaCCRi, pBI-FaCADi, and $\mathrm{pBI}-\mathrm{FaPOD} i$ constructs to co-down-regulate lignin genes (named pBI-Si3) and with Agrobacterium containing pBI-FaCCR, pBI-FaCAD, and pBI-FaPOD constructs to co-up-regulate lignin genes (named pBI-O3). All injected fruits remained attached to the plant until harvested (14 days).

\section{FRUIT FIRMNESS AND LIGNIN HISTOCHEMICAL STAINING}

Fruit firmness was determined by a TA-XT2i texture analyzer (Stable Micro Systems, Godalming, Surrey, UK) according to Bourne (2002), Singh and Reddy (2006). The measuring force was made with a probe of $0.5 \mathrm{~mm}$ in diameter to penetrate the surface of the fruit. Each fruit was penetrated at a speed rate of $1-10 \mathrm{~mm} / \mathrm{s}$. Based on the bio-yield point, the maximum of force developed during the measurement was recorded and expressed in Newtons (N). Each fruit was measured twice on the two opposite sides of the fruit. The penetrated fruit was frozen in liquid nitrogen immediately, and stored at $-80^{\circ} \mathrm{C}$ until used. In addition to Wiesner staining, lignified tissues were visualized according to the method of Blanco-Portales et al. (2002).

\section{ENZYME EXTRACTION AND ASSAYS}

Enzyme extraction was performed according to Chabannes et al. (2001). Briefly, $200 \mathrm{mg}$ of frozen powder (de-achened fruit) was added to $1 \mathrm{ml}$ of extraction buffer consisting of $0.1 \mathrm{M}$ of Tris- $\mathrm{HCl}$ 
(pH 7.5), 2\% PEG 6000 (w/v), 5 mM of DTT, and 2\% PVP K30 $(\mathrm{w} / \mathrm{v})$. Crude protein was extracted by vortexing for $30 \mathrm{~s}$ and incubated on ice for $5 \mathrm{~min}$. After centrifugation at 13,200 rpm for $10 \mathrm{~min}$ at $4^{\circ} \mathrm{C}$, the supernatant was used for the measurement of enzyme activity. In a total volume of $0.5 \mathrm{ml}$, a FaCCR reaction consisted of $100 \mathrm{mM}$ of sodium phosphate $(\mathrm{pH} 6), 100 \mu \mathrm{M}$ of NADPH, $100 \mu \mathrm{M}$ of feruloyl-CoA, and $30 \mu \mathrm{g}$ of crude protein and was incubated at $25^{\circ} \mathrm{C}$ for $30 \mathrm{~min}$. A FaCAD reaction contained $100 \mathrm{mM}$ of sodium phosphate ( $\mathrm{pH} 6.5$ ), $200 \mu \mathrm{M}$ of $\mathrm{NADPH}, 100 \mu \mathrm{M}$ of coniferaldehyde, and $30 \mu \mathrm{g}$ of crude protein and was incubated at $30^{\circ} \mathrm{C}$ for $30 \mathrm{~min}$. Then, the reaction mixture was extracted with ethyl acetate, the solvent was removed and the residue re-dissolved with $30 \mu \mathrm{l}$ of $50 \%$ methanol (v/v) and analyzed by LC-UV-ESI-MS ${ }^{\text {. }}$

\section{EXTRACTION FOR METABOLITE ANALYSIS}

Two hundred and fifty $\mathrm{mg}$ of frozen powder (de-achened fruit) was dissolved in $500 \mu \mathrm{l}$ of methanol containing $50 \mathrm{mg}$ of biochanin $\mathrm{A}$ as an internal standard. The mixture was extracted by vortexing for $1 \mathrm{~min}$, sonicating for $5 \mathrm{~min}$, and centrifuging at $13,200 \mathrm{rpm}$ for $10 \mathrm{~min}$. The supernatant was transferred into a fresh tube and $500 \mu \mathrm{l}$ of methanol was added to the original tube to extract the residue for a second time. The combined supernatant was dried by Speed-Vac, re-dissolved with $35 \mu \mathrm{l}$ of water (LC-MS quality), followed by vortexing for $1 \mathrm{~min}$ and sonicating for $3 \mathrm{~min}$. After centrifugation at 13,200 rpm for $10 \mathrm{~min}$, the supernatant was used for metabolite analysis by LC-UV-ESI-MS ${ }^{\text {. }}$

\section{LIGNIN CONTENT}

The cell wall from $250 \mathrm{mg}$ of frozen powder (de-achened fruit) was prepared according to the method of Meyer et al. (1998) and Franke et al. (2002). Afterwards, the lignin content of sample was determined by thioglycolic-acid assay. Each sample was mixed with $750 \mu \mathrm{l}$ of distilled water, $250 \mu \mathrm{l}$ of $37 \% \mathrm{HCl}$, and $100 \mu \mathrm{l}$ of thioglycolic acid (Sigma-Aldrich, Steinheim, Germany) and incubated at $80^{\circ} \mathrm{C}$ for $3 \mathrm{~h}$. Subsequent steps were described by Campbell and Ellis (1992). Finally, the insoluble lignin was dissolved in $1 \mathrm{ml}$ of $1 \mathrm{M} \mathrm{NaOH}$. The absorbance of the lignin sample was determined spectrophotometrically at $280 \mathrm{~nm}$. The amount of lignin was calculated from a linear calibration curve $(0-20 \mu \mathrm{g})$ with lignin hydrolytic (Sigma-Aldrich, Steinheim, Germany).

\section{LIGNIN COMPOSITION}

De-achened strawberry fruits $(120 \pm 20 \mathrm{~g})$ were cut into small pieces and homogenized using an Ultra Turrax (IKA ${ }^{\circledR}$ Works Inc. Wilmington, NC, USA). Insoluble material was washed until the supernatant was determined to be neutral using $\mathrm{pH}$ indicator paper. Finally, $10 \mathrm{ml}$ of ethanol $(99 \%)$ was added to each sample. Following centrifugation at $5100 \mathrm{rpm}$ for $15 \mathrm{~min}$, the pellets were placed at $37^{\circ} \mathrm{C}$ for drying, overnight. Subsequently, isolation of lignin was performed by the method of Evtuguin et al. (2001), and the resulting lignin was subjected to thioacidolysis (Robinson and Mansfield, 2009). Thioacidolysis products of the samples were analyzed by GC-MS.

\section{LC-UV-ESI-MS}

A Bruker Daltonics esquire $3000^{\text {plus }}$ ion trap mass spectrometer (Bruker Daltonics, Germany) connected to an Agilent 1100
HPLC/UV system with a quaternary pump (Agilent Technologies, Germany) was used. Separation was achieved on a Phenomenex ${ }^{\circledR}$ reversed phase column (Luna $3 \mu \mathrm{m} \mathrm{C18(2)} 100 \AA 150 \times 2 \mathrm{~mm}$ ). Metabolites, CCR, and POD assays were analyzed using a lin-

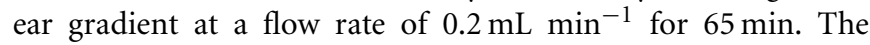
mobile phase A was water with $0.1 \%$ formic acid and B was methanol with $0.1 \%$ formic acid. The gradient condition was $0-50 \% \mathrm{~B}, 0-30 \mathrm{~min}$, then changed to $50-100 \% \mathrm{~B}, 30-35 \mathrm{~min}$, $100 \% \mathrm{~B}, 35-50 \mathrm{~min}, 100-0 \% \mathrm{~B}, 50-55 \mathrm{~min}$, and equilibrated to $0 \% \mathrm{~B}, 55-65 \mathrm{~min}$. The UV detection wavelength was 340 (CCR activity), 320 (POD activity), and $280 \mathrm{~nm}$ (metabolite analysis). To determine CAD activity, the program was run a flow rate of $0.1 \mathrm{~mL} / \mathrm{min}$ with $60 \% \mathrm{~A}$ and $40 \% \mathrm{~B}$ for $30 \mathrm{~min}$ at $260 \mathrm{~nm}$. All acquisitions were performed in the positive and negative ionization mode. Capillary voltage was set to $-4000 \mathrm{~V}$ and the end plate to $-500 \mathrm{~V}$. Nitrogen was used as nebulizer gas ( $30 \mathrm{psi})$ as well as drying gas at $330^{\circ} \mathrm{C}$ and $9 \mathrm{~L} \mathrm{~min}^{-1}$. Full-scan mass spectra were acquired from $\mathrm{m} / \mathrm{z} 100$ to 800 range with a scan resolution of $13,000 \mathrm{~m} / \mathrm{z} / \mathrm{s}$ until the ICC target reached 20,000 or $200 \mathrm{~ms}$, whichever was achieved first. Helium was used as collision gas with $1.0 \mathrm{~V}$ collision voltage. Identity of metabolites was confirmed by comparing the retention times, mass spectra, and product ion spectra of the different compounds in the extracts with those of the reference compounds (Hoffmann et al., 2006). In addition to qualitative identification based on fragmentation patterns and retention times each compound was quantified by using QuantAnalysis 1.5. All results were normalized against the internal standard and expressed as mg-equ. $\mathrm{kg}^{-1}$ (Hoffmann et al., 2006).

\section{GC-MS}

GC-MS analysis was carried out on a Thermo Finnigan Trace DSQ mass spectrometer coupled with a Thermo Finnigan Trace GC 2000 Ultra with a split injector (1:10). Samples were separated on an $\operatorname{Rtx}^{\circledR} 5 \mathrm{~ms}$ fused-silica capillary column $(15 \mathrm{~m} \times$ $0.25 \mathrm{~mm}, d f=0.25 \mu \mathrm{m}$ ) (Restek, Bad Homburg, Germany). The column temperature was held at $90^{\circ} \mathrm{C}$ for $3 \mathrm{~min}$, then increased to $260^{\circ} \mathrm{C}$ at a rate of $5^{\circ} \mathrm{C} \mathrm{min}^{-1}$, and finally maintained at $260^{\circ} \mathrm{C}$ for $15 \mathrm{~min}$. The carrier gas was helium with $1.1 \mathrm{~mL} \mathrm{~min}^{-1}$. The EI-MS ionization voltage was $70 \mathrm{eV}$ (electron impact ionization). The ion source was maintained at $250^{\circ} \mathrm{C}$ and the interface temperature was at $280^{\circ} \mathrm{C}$. GC-MS analysis of trimethylsilylated extracts from treated fruits showed compounds with major ions at $m / z 239,266,299$, and 57 that eluted at retention times of $27.5,29,30.4$, and $23.3 \mathrm{~min}$. Fragment ions and retention times correspond to H-, G-, S- monomers that were liberated by thioacidolysis and to the internal standard docosane (I.S., Fig. S1). Lignin breakdown units of each lignin sample were quantified using Xcalibur software (version 1.4). The H-, G-, and S- monomers were calculated based on the peak area of prominent ions related to that of the internal standard docosane for normalization.

\section{BOX PLOTS AND STATISTICAL ANALYSIS}

The numerical values from different treatments were transformed into box-whisker plot graphics using the software package R (www.r-project.org). Wilcoxon-Mann-Whitney $U$-test was 
used for statistical analysis (Hart, 2001; Hoffmann et al., 2006) due to biological variation of each group. The statistical value ( $P$-value), based on data of two groups, was calculated by the Wilcoxon-Mann-Whitney $U$-test with a non-parametric statistical analysis using the software package R. $P$-value was used to determine whether or not significant differences existed between treatments.

\section{RESULTS}

\section{CHARACTERIZATION AND HETEROLOGOUS EXPRESSION OF FaCCR, FaCAD, FaPOD, AND FaPOD27}

The open reading frame (ORF) of FaCCR is $1017 \mathrm{bp}$, encoding a protein of 339 amino acids with a calculated molecular mass of $37.3 \mathrm{kDa}$ and an isoelectric point (pI) value of 6.12 . Two conserved motifs, NWYCY, which is putatively involved in the catalytic site of CCRs (Pichon et al., 1998) and a second motif, which is the NAD/NADP $(\mathrm{H})$ binding site in the N-terminal portion of CCRs (Lacombe et al., 1997) are present in amino acid sequences of FaCCR (Fig. S2). To determine the biochemical function of FaCCR, the full-length coding region sequence of FaCCR was heterologously expressed in Escherichia coli (Fig. S3). The purified recombinant GST-FaCCR showed a $\mathrm{pH}$ optimum at 6 in sodium phosphate buffer and a temperature optimum at $25^{\circ} \mathrm{C}$ (Fig. S4). The protein exhibited Michaelis-Menten kinetics with apparent $K_{m}$ values of 16.11 (feruloyl-CoA), 25.48 (caffeoylCoA), and $24.75 \mu \mathrm{M}$ ( $p$-coumaroyl-CoA). The $K_{\text {cat }} / K_{m}$ ratios revealed that GST-FaCCR had a high preference for feruloylCoA (1.45 $10^{-4} \mathrm{~s}^{-1} \mu \mathrm{M}^{-1}$; Table 1). In addition to LC-UVESI-MS $^{n}$ analyses of individual enzymatic assays, a GST-FaCCR reaction containing a mixture of equal molar amounts of three substrates (caffeoyl-, p-coumaroyl-, and feruloyl-CoA), yielded three major peaks that were identified as caffeic aldehyde $(3,4$ dihydroxycinnamaldehyde), $p$-coumaraldehyde, and coniferaldehyde, respectively. The retention time for each of the three metabolites (Fig. S5) was identical to that of the single product formed by the GST-FaCCR reaction of the individual substrate (Fig. S6). At the same time, the activity of GST-FaCCR toward the different CoA esters was calculated from the peak areas and indicated that feruloyl-CoA $(100 \%)$ was the preferred substrate compared with both caffeoyl-CoA (3\%) and p-coumaroyl-CoA (3\%) (Fig. S5). These results indicate to a preferential biosynthesis of $\mathrm{G}$ units in strawberry fruit.

FaCAD has a 1077 -bp open reading frame encoding a protein of 359 amino acid residues with a relative molecular mass

Table 1 | Kinetic properties of the recombinant GST-FaCCR protein.

\begin{tabular}{lcccc}
\hline Substrate & $\begin{array}{c}\boldsymbol{K}_{\boldsymbol{m}} \\
(\boldsymbol{\mu} \mathbf{M})\end{array}$ & $\begin{array}{c}\boldsymbol{V}_{\text {max }} \\
\text { (nkat } \mathbf{~ m g}^{-\mathbf{1}} \\
\text { protein) }\end{array}$ & $\begin{array}{c}\boldsymbol{K}_{\text {cat }} \\
\left.\mathbf{( S}^{-\mathbf{1}}\right)\end{array}$ & $\begin{array}{c}\boldsymbol{K}_{\text {cat }} / \boldsymbol{K}_{\boldsymbol{m}} \\
\left(\mathbf{S}^{-\mathbf{1}} \boldsymbol{\mu} \mathbf{M}^{-\mathbf{1}}\right)\end{array}$ \\
\hline Feruloyl-CoA & $16.11 \pm 1.39$ & $272.45 \pm 15.9$ & $2.34 \times 10^{-3}$ & $1.45 \times 10^{-4}$ \\
Caffeoyl-CoA & $25.48 \pm 0.82$ & $3.75 \pm 0.24$ & $2.93 \times 10^{-5}$ & $1.15 \times 10^{-6}$ \\
p-Coumaroyl- & $24.75 \pm 1.23$ & $3.12 \pm 0.03$ & $2.65 \times 10^{-5}$ & $1.07 \times 10^{-6}$ \\
CoA & & & & \\
\hline
\end{tabular}

Values are the mean \pm SE for three independent assays. of $39 \mathrm{kDa}$ and a pI value of 5.96. FaCAD is highly similar to Fxacad1 (F. $\times$ ananassa cv. Chandler; 98.1\% identity) and PtSAD (Populus tremuloides, 77.9\% identity) which exhibit different substrate preferences (Li et al., 2001; Blanco-Portales et al., 2002). A conserved NAD/NADP(H) binding sites as well as $\mathrm{Zn} 1$ and $\mathrm{Zn} 2$ binding motifs are present in the three proteins (Fig. S7). Thus, the FaCAD protein appears to be a zincdependent alcohol dehydrogenase. In addition, the full-length coding region of $\mathrm{FaCAD}$ was subcloned into a pYES2 vector and was expressed in yeast cells (Saccharomyces cerevisae INVSc.1). LC-UV-ESI-MS ${ }^{n}$ analysis indicated that extracellular FaCAD activity slightly increased when $F a C A D$ was expressed in yeast cells and showed that coniferyl alcohol was generated (Fig. S8). Thus, FaCAD may be involved in the regulation of lignin biosynthesis and contribute to the production of $G$ units in strawberry fruit.

The open reading frame of FaPOD is 990 nucleotides in length and encodes a protein of 330 amino acids with a molecular mass of $37.6 \mathrm{kDa}$ and a pI value of 7.7. FaPOD27 has a 990-bp open reading frame corresponding to a $35.1-\mathrm{kDa}$ protein consisting of 330 amino acids with a calculated pI of 8.47 (Ring et al., 2013). The Prosite analysis (http://prosite.expasy.org/) revealed that FaPOD and FaPOD27 (Ring et al., 2013) are plant heme peroxidases. They both contain a putative $\mathrm{Ca}^{2+}$ binding domain and belong to the family of class III peroxidases but exhibit a low percentage of identical amino acids (31.9\%). The full-length coding region sequences of $\mathrm{FaPOD}$ or $\mathrm{FaPOD} 27$ were heterologously expressed in E. coli and assayed with different substrates. Since ferulic acid and coniferyl alcohol were almost completely oxidized in the presence of $\mathrm{H}_{2} \mathrm{O}_{2}$ and FaPOD27 the products were subjected to LC-UV-ESI-MS ${ }^{n}$ analysis (Fig. S9, Ward et al., 2001; Ring et al., 2013). A dehydrodimer of ferulic acid (M.W. $386 \mathrm{~g} / \mathrm{mol}$ ) and products formed by decarboxylation of a dehydrodimer precursor (M.W. $342 \mathrm{~g} / \mathrm{mol}$ ) were found as major products (Fig. S9). Unlike FaPOD27, these compounds were not produced by FaPOD or control GST. The results indicate that FaPOD27 is presumably associated with polymerization of coniferyl alcohol and to a lower extent of ferulic acid in lignin. Enzymatic activity of FaPOD could not be detected.

\section{EXPRESSION OF LIGNIN BIOSYNTHETIC GENES IN DIFFERENT PARTS OF THE PLANT}

Gene expression studies in F. $x$ ananassa cv. Elsanta by qRTPCR revealed low transcript levels of both $F a C C R$, and FaCAD in unripe fruit from SG (small green) to $\mathrm{W}$ (white) stage and for $\mathrm{FaPOD} 27$ from SG to T (turning) stage (Figure 2). However, high expression levels of the genes were detected in the mature fruit (T/R for FaCCR and FaCAD and $\mathrm{R}$ in the case of FaPOD27). Besides, low mRNA levels of the genes were detected in vegetative tissues and flowers, except for FaCAD and FaPOD27 which were highly expressed in the root. Contrastingly, the highest gene expression level of FaPOD was detected in the SG stage and then decreased to almost undetectable levels at the red stage (R). Varied expression levels were detected in vegetative tissues and flowers. Thus, FaCCR, FaCAD, and FaPOD27 genes are strongly expressed in the ripe red fruit, except for FaPOD, which is primarily transcribed in the SG fruit. 
A
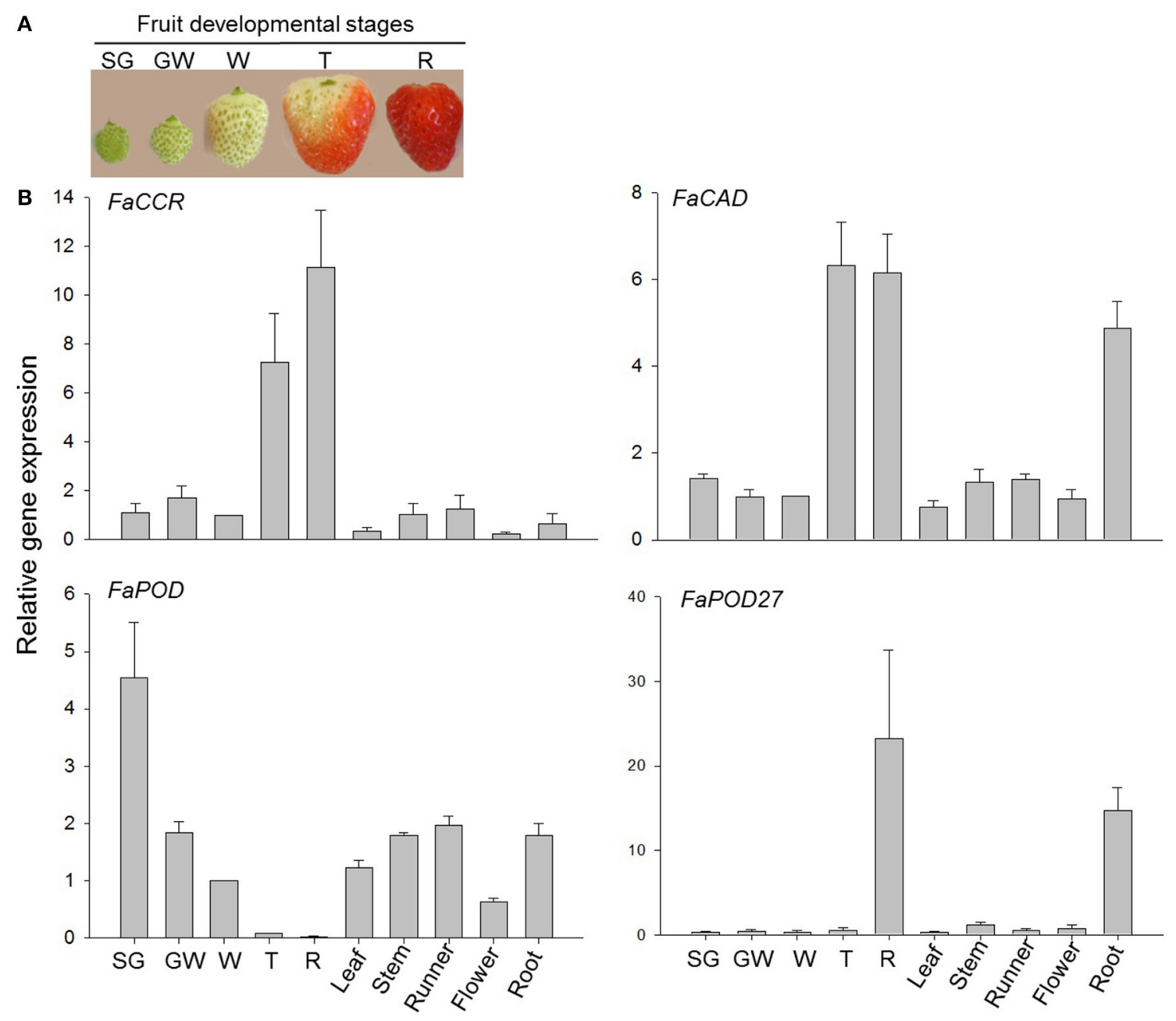

FIGURE 2 | Relative expression profiles of monolignol biosynthesis genes in vegetative tissues, flowers, and fruit developmental stages of

F. $x$ ananassa cv. Elsanta. Total RNA was isolated from (A) fruit

developmental stages at small green (SG), green white (GW), white (W),

turning $(T)$, and red (R) after pollination. (B) Expression levels of vegetative

\section{EXPRESSION OF FaPOD27 IS INDUCED IN RESPONSE TO AGROBACTERIUM}

Lignin biosynthesis is a multi-step pathway, where several genes and enzymes can be induced by various abiotic (plant injuries) and biotic (bacterial infection) stresses (Moura et al., 2010). As agroinfiltration was used in this study to overexpress and down-regulate lignin biosynthesis genes in strawberry fruit, the effect of agroinfiltration on phenylpropanoid metabolism was investigated. Agroinfiltrated fruits were exposed to wounding (perforation of the fruit epidermis by a syringe) and coincidentally to pathogen infection (Agrobacterium tumefaciens). Thus, the effect of wounding (injection of MMA buffer) and Agrobacterium infection on the expression of putative phenylpropanoid biosynthesis genes was analyzed independently in the fruit. As a result, no significant induction of $F a P A L, F a C C R$, $F a C A D, F a P O D$, and FaPOD27 genes were detected in the wounded fruits, as compared to control (untreated) fruits during $48 \mathrm{~h}$ (Fig. S10). Moreover, no significant induction of $\mathrm{FaCHS}$, $F a C C R, F a C A D$, and $F a P O D$ genes were detected in the fruits exposed to Agrobacterium, as compared to control fruits during 4 days (Figure 3). It even appeared that their expression levels were reduced upon agroinfiltration. However, FaPAL transcripts were transiently induced at $24 \mathrm{~h}$. In contrast, FaPOD27 transcript levels in the fruits injected with Agrobacterium gradually started to increase at $6 \mathrm{~h}$ and reached a high level at $96 \mathrm{~h}$ which was more than 180-fold higher than in control fruit (Figure 3 ). Also, FaPOD27 transcripts were constitutively induced more than 1500-fold within 1-10 days in fruits exposed to Agrobacterium (Ring et al., 2013). Thus, FaPOD27 transcripts are strongly upregulated in fruits as a response to infection with Agrobacterium, suggesting that this gene plays an important role in pathogen defense. 


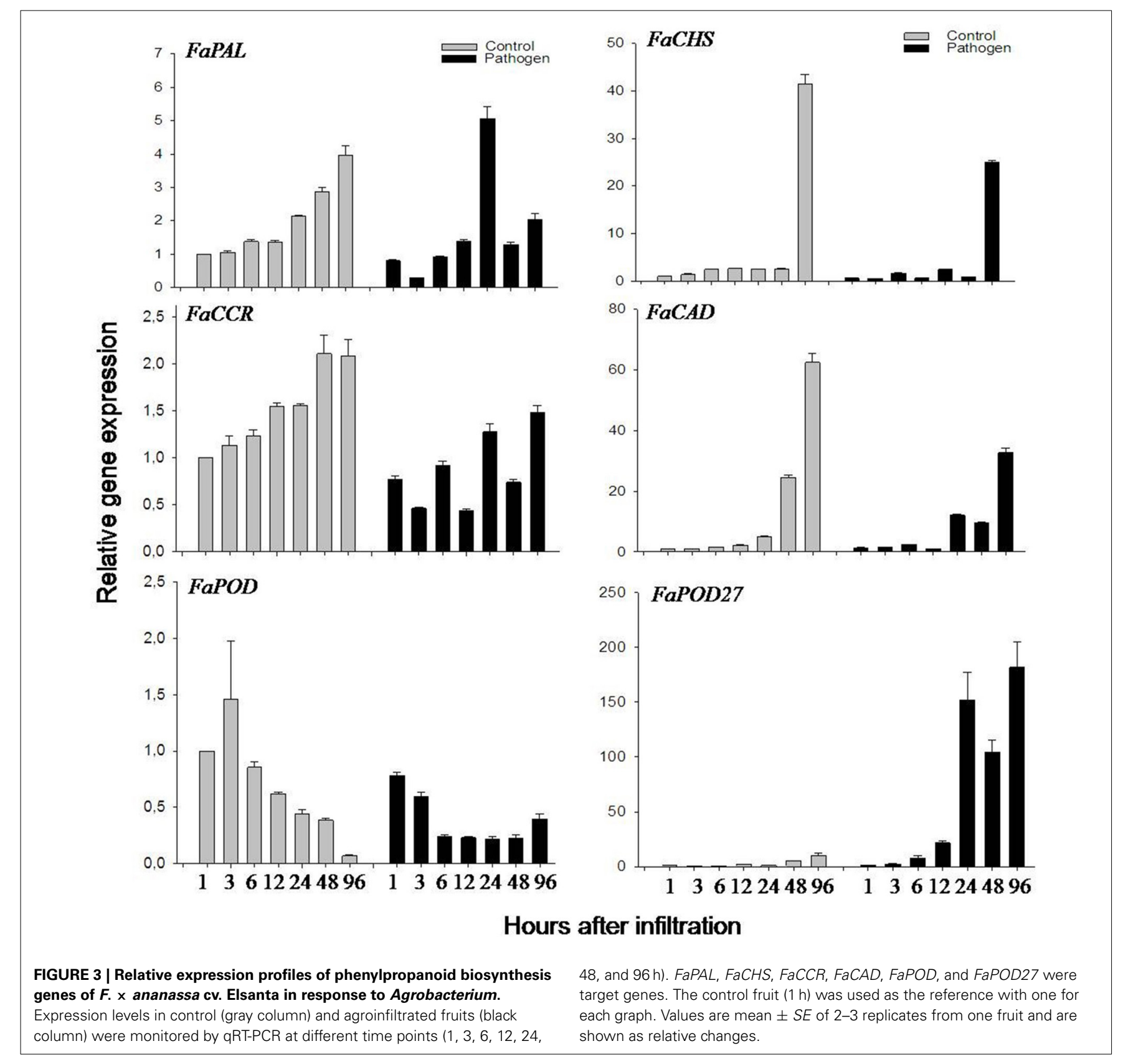

\section{EFFECT OF WOUNDING AND PATHOGEN INFECTION ON FRUIT FIRMNESS}

To test whether strawberry fruit respond to stress with increased firmness, fruits were either infiltrated with MMA medium (wounding), or infiltrated with Agrobacterium (pathogeninfection). Fruit firmness was measured at 14 days after infiltration (Figure 4). Fruit firmness was significantly increased $(P=4.33 \mathrm{E}-05)$ in fruits infiltrated with Agrobacterium, but not in wounded fruits $(P=9.72 \mathrm{E}-01)$ as compared to untreated WT fruits. Both wounded and wild-type fruits were soft, whereas fruits infiltrated with Agrobacterium tended to be hard. The result suggests that fruit firmness significantly increased following infiltration with Agrobacterium.

\section{DOWNREGULATION AND OVEREXPRESSION OF LIGNIN BIOSYNTHESIS} GENES BY ihPRNA AND OVEREXPRESSION CONSTRUCTS IN FRUIT

In order to manipulate the quantity and quality of lignin in strawberry fruit, we utilized an ihpRNA- and overexpression-cassette with individual $F a C C R$, FaCAD, and FaPOD to silence and overexpress $F a C C R, F a C A D$, and FaPOD in the fruit. Fruits harboring pBI-intron served as control fruits (Figure 5A). Phenotypic analysis showed that the texture of the fruits injected with different constructs was more solid than that of the untreated fruits (WT). Untreated and treated fruits (pBI-intron control fruits, FaCCR-, FaCAD-, FaPOD-downregulated, FaCCR-, FaCAD-, or FaPOD-upregulated fruits) had retained their red color and were similar in appearance (Figure 5BI). In addition, all treated fruits 


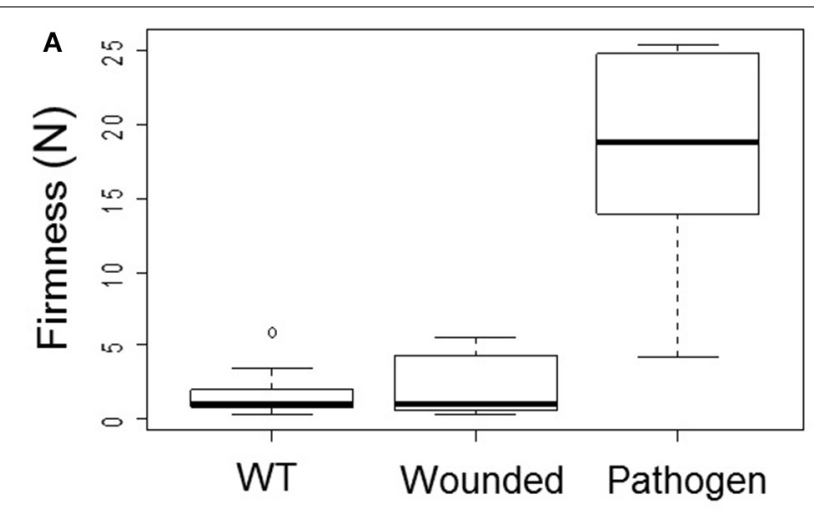

B

\begin{tabular}{ll}
\hline Two groups & $P$-value \\
\hline WT vs. Wounded & $9.72 \mathrm{E}-01$ \\
WT vs. Pathogen & $4.33 \mathrm{E}-05$ \\
\hline
\end{tabular}

FIGURE 4 | Effect of wounding and pathogen infection on fruit firmness of $\boldsymbol{F} \quad \mathbf{x}$ ananassa cv. Elsanta. (A) WT (Wild type; $n=10$ ); fruits infiltrated with MMA medium (wounded; $n=12$ ) and Agrobacterium (pathogen; $n=10$ ). (B) The Wilcoxon-Mann-Whitney $U$-test was used for a non-parametric comparison of two groups from WT and wounded or pathogen-infected fruits. Values showing statistically significant increased levels $(P<1.00 \mathrm{E}-02)$ are marked by a yellow background.

showed the formation of pink-red colors around vascular bundles within $30 \mathrm{~min}$ after lignin staining. In contrast, slight pinkred colors were observed in the untreated fruits (Figure 5BII). This result suggests native lignin around vascular bundles is induced by Agrobacterium infiltration. The accumulation of lignin in fruits infiltrated with different constructs (Figure 5A) might be a defense reaction of the fruit to resist Agrobacterium invasion.

Both, firmness and lignin content was significantly increased in treated fruits (pBI-intron, $\mathrm{pBI}-F a C C R i$, pBI-FaCADi, pBI$F a P O D i$, pBI-FaCCR, pBI-FaCAD, and pBI-FaPOD fruits) in comparison with untreated fruits (WT; Figure 6). In addition, comparison of $\mathrm{pBI}$-intron control fruits (agroinfiltrated with a control vector) with the other treated fruits showed that firmness and lignin content were not affected significantly. Thus, when individual $F a C C R, F a C A D$, and $F a P O D$ were down-regulated and up-regulated in the fruits by agroinfiltration, up-regulation of defense genes such as FaPOD27 affected fruit firmness and lignin to a much larger extent than the transgenes.

The effect of untreated and treated fruits on the metabolite levels was analyzed by LC-UV-ESI-MS ${ }^{\mathrm{n}}$. Major compounds (phenolic acid derivatives, flavonols, anthocyanins, and proanthocyanidins) were quantified. The levels of flavonoids (flavonols, anthocyanins, and proanthocyanidins) were not significantly changed in treated fruits compared with either WT (untreated) fruits or pBI-intron control fruits. In general, the metabolites, whose levels were significantly different between untreated and agroinfiltrated fruits were phenolic acid derivatives ( $p$-coumaroyl glucoside/glucose, caffeoyl glucose, and feruloyl glucose, Figure 1 and Fig. S11).

Quantitative real time-PCR was performed to estimate the expression levels of phenylpropanoid biosynthesis genes in FaCCR-, FaCAD-, FaPOD-down-regulated, FaCCR-, FaCAD-, and FaPOD-up-regulated fruits (Figure 7). Transcript levels of both $\mathrm{FaPAL}$ and $\mathrm{FaCHS}$ were not significantly changed in these fruits (data not shown). However, in comparison to pBI-intron control fruits, $F a C C R$ and $F a C A D$ transcripts were significantly decreased $(P<0.05)$ in $\mathrm{pBI}-F a C C R i$ and $\mathrm{pBI}-F a C A D i$ fruits, respectively (Figure 7A). They were not significantly different in other treated fruits. Thus, the ihpRNA-FaCCR and $-F a C A D$ construct showed sequence-specific interference with homologous $\mathrm{FaCCR}$ and $\mathrm{FaCAD}$ expression in the fruits. However, $F a P O D$ transcripts were not significantly affected in pBI-FaPOD $i$ fruits (Figure 7A) probably due to the already low expression level of FaPOD in the ripe red fruit (Figure 2B). In the case of up-regulation of monolignol genes in the fruits, expression levels of $F a C C R$ and $F a C A D$ were not significantly affected in $\mathrm{pBI}-\mathrm{FaCCR}$ and $\mathrm{pBI}-\mathrm{FaCAD}$ fruits (Figure 7B). FaCCR and $\mathrm{FaCAD}$ transcripts are already abundant in the ripe red stage of WT fruit (Figure 2B) but their levels did not increase in pBI$F a C C R$ and pBI-FaCAD fruits (Figure 7B). Interestingly, levels of $F a P O D$ transcripts which are rarely expressed in the ripe red stage (Figure 2B) increased significantly $(P<0.05)$ when FaPOD was overexpressed in pBI-FaPOD fruits (Figure 7B). Besides, the effect of untreated and treated fruits (FaCCR- and FaCADdownregulated and -upregulated fruit) on enzyme activities was analyzed by LC-UV-ESI-MS ${ }^{\mathrm{n}}$. FaCCR and FaCAD activity was reduced in $\mathrm{pBI}-\mathrm{FaCCR} i$ and $\mathrm{pBI}-\mathrm{FaCAD} i$ but also in $\mathrm{pBI}-\mathrm{FaCCR}$ and $\mathrm{pBI}-\mathrm{FaCAD}$ fruits (Figure 8) in comparison with untreated WT fruit. The dsRNA produced by $\mathrm{pBI}-\mathrm{FaCCR} i$ and $\mathrm{pBI}-\mathrm{FaCAD} i$ can trigger PTGS (post-transcriptional gene silencing) to interfere with homologous $\mathrm{FaCCR}$ and $\mathrm{FaCAD}$ expression. Co-suppression of homologous genes can, at least in parts, explain the observation of reduced CCR and CAD activity in pBI-FaCCR and pBI-FaCAD fruits.

To determine lignin composition and estimate proportions of lignin monomers, lignin was extracted from pooled fruits of each treatment and was subjected to thioacidolysis. H-, G-, and S-monomers were not detected in WT (untreated) fruits due to the low yield of lignin produced in these fruits (Table 2). In contrast, H-, G-, and S-monomers were detected in all treated fruits, because higher levels of lignin accumulated in the fruits exposed to Agrobacterium. In comparison to $\mathrm{pBI}$-intron control fruits, low amounts of $\mathrm{H}$-monomers were detected in all treated fruits. FaCAD-silenced fruits showed a significant reduction of $58 \%$ in $\mathrm{H}$-monomers. Levels of G-monomers were significantly reduced by 35,33 , and $32 \%$ in the $\mathrm{pBI}-F a C C R i, \mathrm{pBI}-F a C A D i$, and pBI-FaPOD fruits, respectively. Levels of S-monomers were significantly reduced by 22 and $13 \%$ in $\mathrm{pBI}-\mathrm{FaCAD} i$ and $\mathrm{pBI}-\mathrm{FaPOD}$ fruits, respectively. However, amount of S-monomers was significantly elevated by $18 \%$ in the pBI-FaCCR fruits. Remarkably, levels of both G- and S-monomers were significantly reduced in the $\mathrm{pBI}-\mathrm{FaCAD} i$ and $\mathrm{pBI}-\mathrm{FaPOD}$ fruits. In addition, $\mathrm{FaCCR}$ silenced fruits showed the highest increase in the $S / G$ ratio $(1.36 \pm$ 0.12) of lignin, as compared to all treatments (Table 2). 


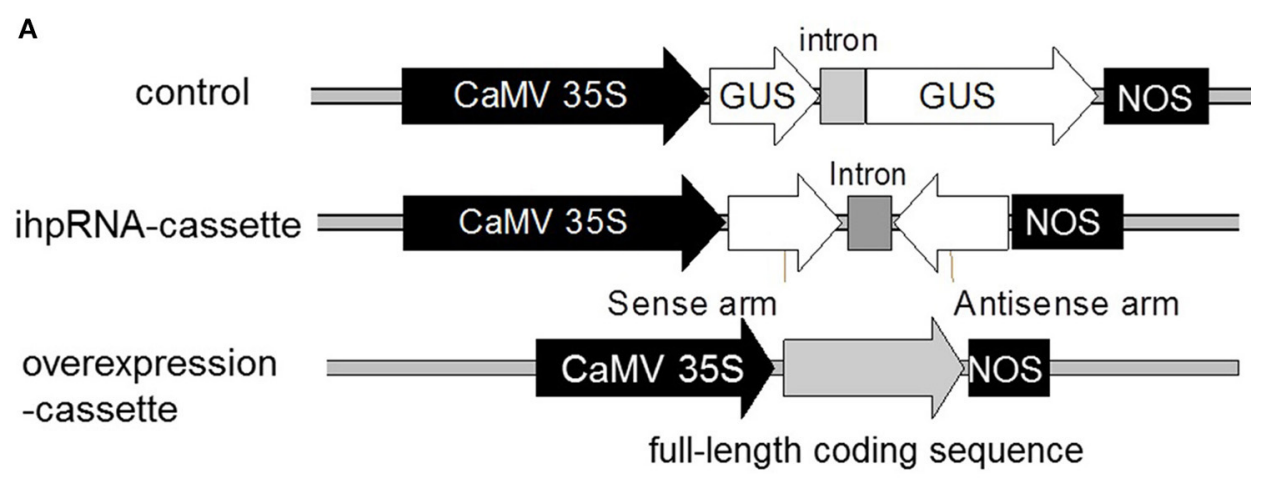

B
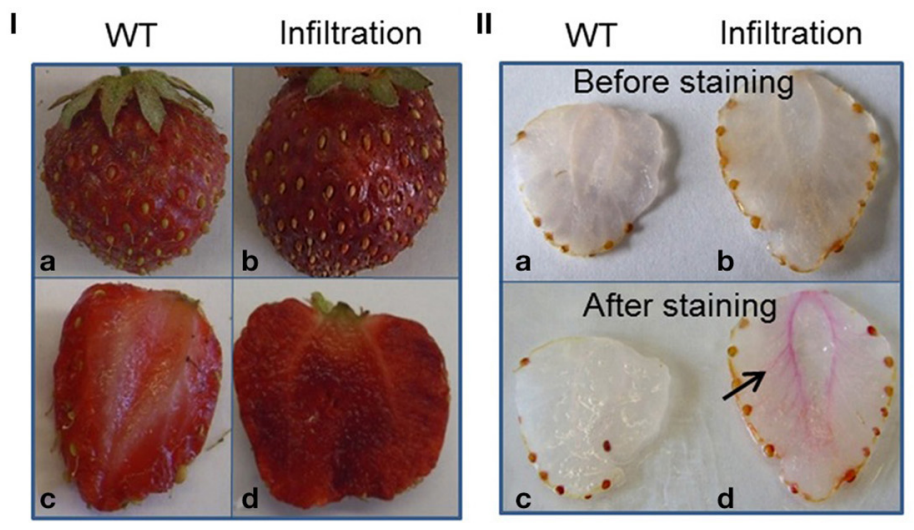

FIGURE 5 | Schematic diagram of constructs (A), and phenotype (I) and lignin staining (II) of wild-type and infiltrated fruits (B). (A) All constructs are in the binary vector pBI121. CaMV 35S, the 35S promoter of cauliflower mosaic virus; intron, the second intron of strawberry FaQR gene (Raab et al. 2006); NOS, terminator of the nopaline synthase gene. A control construct (pBI-intron) contained a GUS gene interrupted by an intron; an inpRNAcassette construct contained an intron flanked by partial coding sequences (300 bp) of target genes ( $F a C C R, F a C A D$, or FaPOD) in sense and antisense orientations; an overexpression-cassette comprised the full-length coding sequence of target genes ( $F a C C R, F a C A D$, or FaPOD). All constructs were used for agroinfiltration of fruits. (B) All photographs were taken 14 days after infiltration. WT (Wild type; a, c) was used as a non-infiltrated fruit. Infiltrated fruits are those injected with Agrobacterium suspensions harboring different constructs, as described in (A). (I) Phenotypes of WT (a, c) and infiltrated fruits (b, d). (II) Cross-sections of WT (a, c; $n=2)$ and infiltrated fruits (b, d; $n=2$ ) before and after Wiesner staining. The arrow indicates native lignins in the fruit infiltrated with Agrobacterium suspensions harboring different constructs, as described in (A).

\section{INDIVIDUAL OR COMBINED DOWN- OR UP-REGULATION OF MONOLIGNOL GENES IN CHS-DEFICIENT (CHS-) FRUIT}

$p$-Coumaroyl-CoA is the common substrate of CHS, HCT, and CCR enzymes in the phenylpropanoid metabolism (Figure 1). When the CHS gene is silenced in fruits, the pool of $p$-coumaroylCoA increases (Lunkenbein et al., 2006) and could provide additional precursors ( $p$-coumaroyl-CoA) for the synthesis of H-, G-, and S-lignin. In this work, individual and combined down- and up-regulation of monolignol genes was also performed by agroinfiltration in fruits of stable transgenic antisense CHS Calypso $\left(\mathrm{CHS}^{-}\right)$lines. CHS-deficient fruits injected with different constructs (infiltration) remained white or only slightly red in color, whereas fruits with impaired $\mathrm{CHS}\left(\mathrm{CHS}^{-}\right)$turned pink and control wild-type fruits $\left(\mathrm{CHS}^{+}\right)$developed a red color (Figure 9). Fruits of the $\mathrm{CHS}^{-}$line carry the antisense $\mathrm{CHS}$ gene that results in lower formation of anthocyanins in comparison to fruits of WT plants but pigment formation is further reduced by agroinfiltration independent of the construct used. In the CHSi-deficient background, transcriptional profiles of phenylpropanoid biosynthesis genes in fruits agroinfiltrated to down- and up-regulate genes of the monolignol pathway were quite consistent with the results from Elsanta fruits (Fig. S12 and Figure 7). Levels of $F a C C R$ and $F a C A D$ transcripts were significantly reduced in $\mathrm{FaCCR}$ - and $\mathrm{FaCADi}$-silenced $\mathrm{CHS}^{-}$ fruits, whereas FaPOD mRNA levels were considerably increased in FaPOD-overexpressed fruits (Fig. S12) in comparison to the results in $\mathrm{CHS}^{-}$controls. An exception was FaPAL whose transcript level was remarkably reduced in pBI-FaCADi fruit.

In addition, the effect of down- and up-regulation of monolignol biosynthesis genes on texture and lignin content in $\mathrm{CHS}^{-}$ fruits was investigated. The comparison of firmness and lignin content of $\mathrm{CHS}^{-}$(untreated fruit) with $\mathrm{CHS}^{-} / \mathrm{pBI}$-intron control fruit and the other treated fruits $\left(\mathrm{CHS}^{-}\right.$fruits agroinfiltrated to down- and up-regulate monolignol genes) showed that fruit firmness and the amount of lignin is primarily affected by agroinfiltration as injection of Agrobacterium carrying the control vector already increases firmness and lignin content to high levels (Figure 10). 

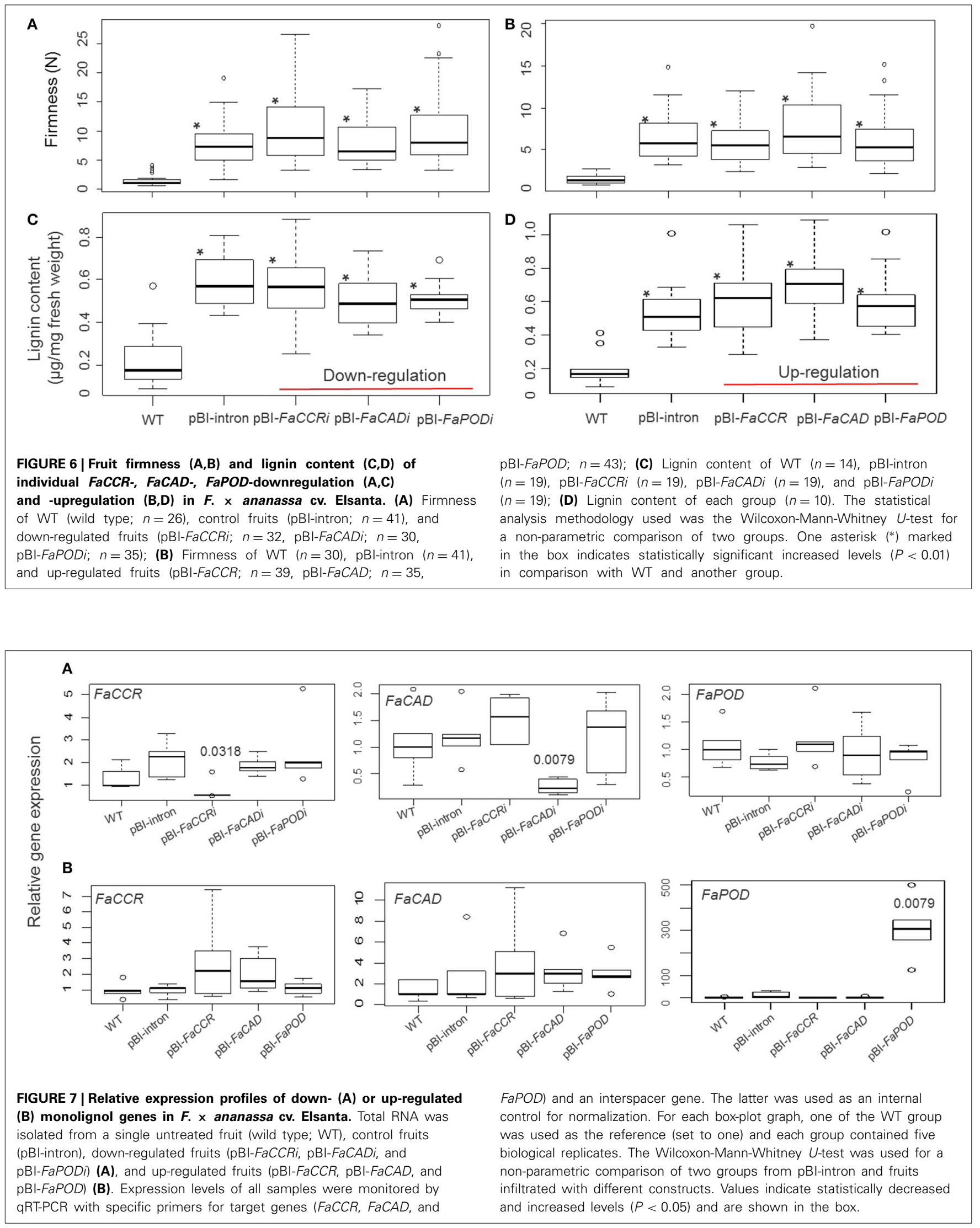


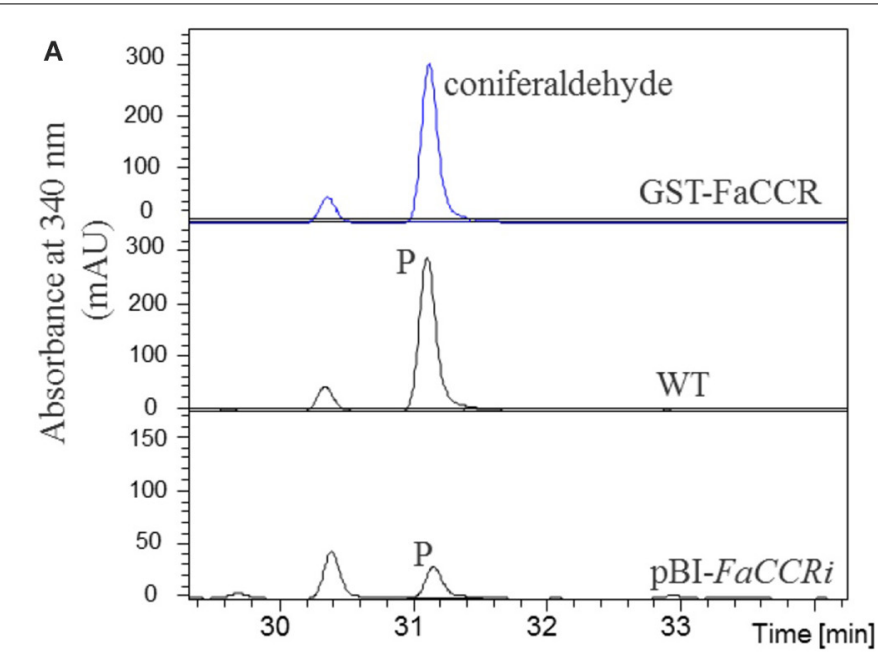

C

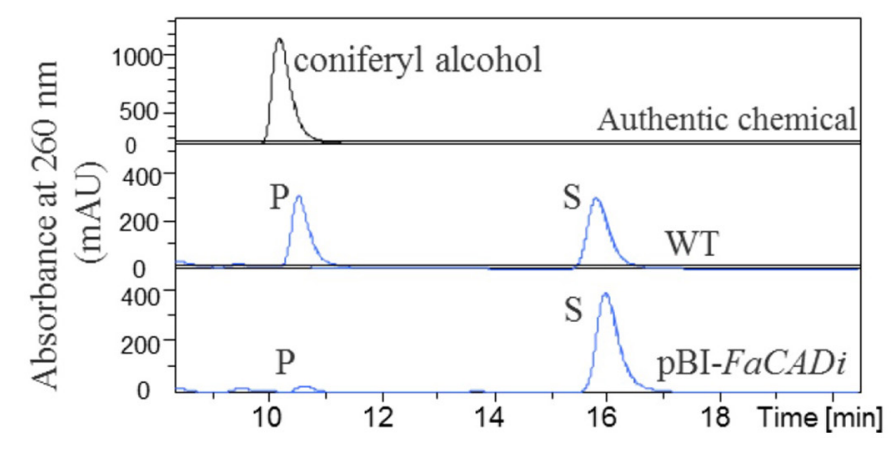

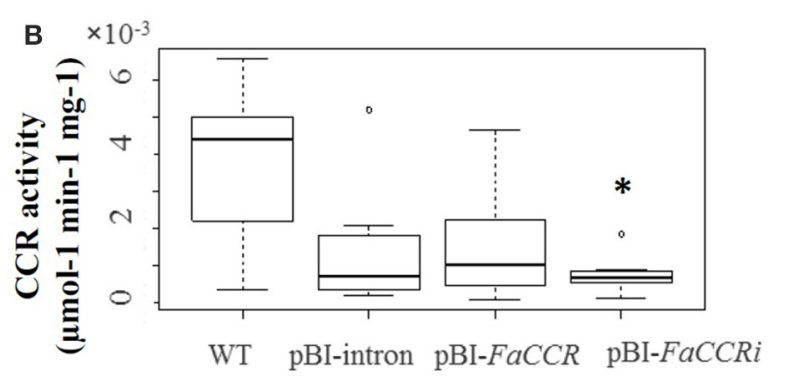

D

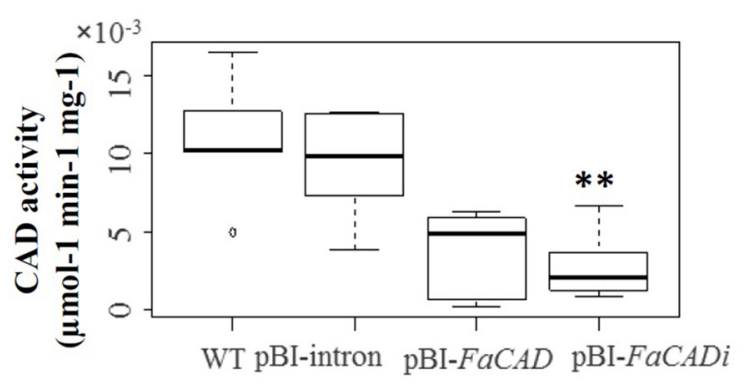

FIGURE 8 | CCR (A,B) and CAD (C,D) specific activity in wild-type and agroinfiltrated fruits. (A) Coniferaldehyde ( $P$; products) formed in the reactions was quantified at $340 \mathrm{~nm}$. (B) Untreated fruits (WT), control fruits (pBI-intron), pBI-FaCCR, and $\mathrm{pBI}-F a C C R i$; each group $n=7$. (C) Coniferyl alcohol formed in the reactions $(P=$ coniferyl alcohol; $S=$ coniferaldehyde) was quantified at $260 \mathrm{~nm}$. (D) WT, pBI-intron, pBI-FaCAD, and $\mathrm{pBI}-$ FaCADi fruits; each group $n=6$. The Wilcoxon-Mann-Whitney $U$-test was used for a non-parametric comparison of two groups. One asterisk $\left(^{*}\right)$ or two asterisks $\left(^{* *}\right)$ in the box mark statistically significant decreased levels $(P<0.02)$ in comparison with WT and another group (indicated by $*$ ), or in comparison with either WT or pBI-intron and another group (indicated by ${ }^{* *}$ ).

\section{DISCUSSION \\ BIOCHEMICAL CHARACTERIZATION OF FaCCR, FaCAD, FaPOD AND FaPOD27}

As comparative microarray analyses have provided first evidence for a contribution of lignin in strawberry fruit firmness (Salentijn et al., 2003) we analyzed the role of lignin biosynthesis genes in fruit ripening. The activity of the CCR enzyme has already been observed in several plant species. Our in vitro results indicate that FaCCR is optimal at $\mathrm{pH} 6.0$ in a $100 \mathrm{mM}$ sodium phosphate buffer at $25^{\circ} \mathrm{C}$. Similarly, soybean CCR activity exhibited an optimum at $\mathrm{pH} 6.0-6.2$ in $100-200 \mathrm{mM}$ citrate buffer at $30^{\circ} \mathrm{C}$ and was stable at around pH 7.0 (Wengenmayer et al., 1976) whereas eucalyptus CCR activity was optimal at $\mathrm{pH}$ 5.3-6.5 in a potassium/sodium phosphate buffer (Goffner et al., 1994). In addition, FaCCR exhibited the highest affinity with feruloyl-CoA. This was quite consistent with other angiosperm CCR proteins, which convert feruloyl-CoA with greater efficiency (Lauvergeat et al., 2001; Li et al., 2005). The poor conversion rate of CCRs with $p$ coumaroyl-CoA explains the low content of $\mathrm{H}$ units in the lignin of angiosperms (Li et al., 2005). Feruloyl-CoA and sinapoyl-CoA would be converted into $\mathrm{G}$ and $\mathrm{S}$ monomers, respectively, via an independent or cross route, and eventually, heterologous G-S lignin is formed in angiosperms (Dixon et al., 2001).

FaCAD and Fxacad1 (F. $\times$ ananassa cv. Chandler) proteins share $98.1 \%$ amino acid identity. In in vitro studies, pYES2-FaCAD was successfully expressed in S. cerevisiae and low amount of coniferyl alcohol product was generated (Fig. S8). Besides, the recombinant Fxacad1 enzyme expressed in Pichia pastoris cells exhibited high activity with cinnamyl (100\% activity), coniferyl (51.2\%), and sinapyl (64.3\%) aldehyde (BlancoPortales et al., 2002). This suggests that FaCAD is a putative NADPH-dependent cinnamyl alcohol dehydrogenase.

Two strawberry peroxidases, FaPOD and FaPOD27, which belong to the group of plant heme peroxidase, have been analyzed in this study. Recombinant FaPOD27 was successfully produced in E. coli and crude protein extracts containing FaPOD27 oxidized putative lignin precursors such as coniferyl alcohol, ferulic acid, and caffeic acid, in the presence of $\mathrm{H}_{2} \mathrm{O}_{2}$ into dehydrodimers. The reactivity of FaPOD27 strongly suggests a function of this enzyme in the polymerization of phenolics (Ring et al., 2013). However, 
Table 2 | Impact of fruits injected with different constructs on lignin monomer composition.

\begin{tabular}{|c|c|c|c|c|}
\hline \multirow[t]{3}{*}{ WT } & \multirow{2}{*}{\multicolumn{3}{|c|}{$\begin{array}{c}\text { Relative concentration }(\%, \mathrm{ML}) \\
\begin{array}{c}\text { Proportion of thioacidolysis } \\
\text { monomers }\end{array}\end{array}$}} & \multirow[b]{3}{*}{$\begin{array}{c}\text { S/G ratio } \\
\text { ND }\end{array}$} \\
\hline & & & & \\
\hline & $\begin{array}{c}\text { H } \\
\text { ND }\end{array}$ & $\begin{array}{c}\text { G } \\
\text { ND }\end{array}$ & $\begin{array}{c}S \\
\text { ND }\end{array}$ & \\
\hline pBI-intron & $0.19 \pm 0.04$ & $3.83 \pm 0.05$ & $3.65 \pm 0.11$ & $0.95 \pm 0.04$ \\
\hline pBI-FaCCRi & $0.14 \pm 0.09$ & $2.50 \pm 0.37^{*}$ & $3.38 \pm 0.21$ & $1.36 \pm 0.12^{*}$ \\
\hline $\mathrm{pBI}-F a C A D i$ & $0.08 \pm 0.02 *$ & $2.55 \pm 0.08^{*}$ & $2.85 \pm 0.17^{*}$ & $1.12 \pm 0.10$ \\
\hline pBI-FaPODi & $0.13 \pm 0.02$ & $3.93 \pm 0.01$ & $4.09 \pm 0.27$ & $1.04 \pm 0.07$ \\
\hline $\mathrm{pBI}-\mathrm{FaCCR}$ & $0.17 \pm 0.03$ & $4.02 \pm 0.22$ & $4.29 \pm 0.03^{*}$ & $1.07 \pm 0.05$ \\
\hline $\mathrm{pBI}-F a C A D$ & $0.16 \pm 0.02$ & $3.41 \pm 0.23$ & $4.17 \pm 0.44$ & $1.22 \pm 0.05^{*}$ \\
\hline $\mathrm{pBI}-\mathrm{FaPOD}$ & $0.10 \pm 0.004$ & $2.62 \pm 0.01^{*}$ & $3.19 \pm 0.03^{*}$ & $1.22 \pm 0.02^{*}$ \\
\hline
\end{tabular}

For each treatment, fruits $(120 \pm 20 \mathrm{~g})$ were pooled to extract lignin. Values are the means \pm s.e.m. of duplicates of two independent analyses from the pooled lignin. $M L$, monomeric lignin; ND, not detected. One asterisk $\left({ }^{*}\right)$ indicates significant differences by Student t-test $(P<0.01)$ in comparison with $p B$-inron and another treatment.

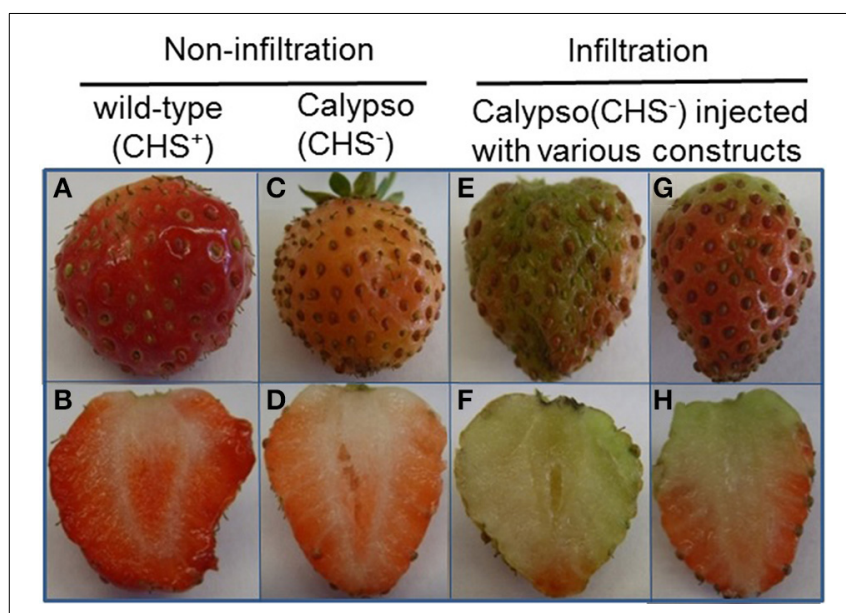

FIGURE 9 | Comparison of non-infiltrated and infiltrated Calypso (CHS $^{-}$) fruits. All pictures were taken 14 days after infiltration. Phenotypes of non-infiltrated (A-D) and infiltrated fruits (E-H) are compared. Non-infiltrated fruits of Calypso with $\mathrm{CHS}$ genes $\left(\mathrm{CHS}^{+} ; \mathbf{A}, \mathbf{B}\right)$ and Calypso with impaired $\mathrm{CHS}$ genes $\left(\mathrm{CHS}^{-} ; \mathbf{C}, \mathbf{D}\right)$ are shown. Infiltrated fruits (E-H) represent Calypso fruit $\left(\mathrm{CHS}^{-}\right)$injected with Agrobacterium suspensions harboring either pBI-intron, FaCCR-, FaCAD-, FaPOD-ihpRNA, FaCCR-, FaCAD-, FaPOD-overexpression constructs, or combined pBI-Si3 and pBI-O3 constructs. All agroinfiltrated fruits showed a similar phenotype (E-H).

recombinant FaPOD was poorly expressed in E. coli and remained inactive when tested with putative lignin precursors. Two AGA and AGG codons were found 28 times in the full-length coding sequence of $F a P O D$. Since prokaryotes rarely employ tRNAs for AGA and AGG arginine codons, genes containing these codons can hardly be expressed in regular E. coli strains (Hushpulian et al., 2003). However, active AtPOD33, AtPOD34, and AtPOD37 proteins have been expressed in eukaryotic host baculovirusinsect cells (Carpin et al., 2001). Peroxidases can be expressed in such hosts, where the native proteins fold correctly and act as functional proteins. This system was not yet used for the heterologous expression of FaPOD. However, FaPOD gene expression data suggest a role in early stages of fruit development (Figure 2).

\section{FRUITS IN RESPONSE TO AGROBACTERIUM ATTACK}

Inducing the expression of defense-related genes and coordinating complex interactions between defense-signaling pathways are major factors in activating a defense response against pathogen attack in plants (Rushton and Somssich, 1998). PAL, COMT, 4CL, CAD, and POD showed transiently increased activity in pine cell culture following treatment with an elicitor derived from an ectomycorrhizal fungus (Campbell and Ellis, 1992). The expression of peroxidase genes was induced in both the epidermis and mesophyll tissues in wheat after Bgt attack (Liu et al., 2005). In the present study, expression of FaPOD27 was clearly induced in fruits after infection with Agrobacterium. FaPOD27 showed a low basal expression in different tissues but its transcript levels constantly and significantly increased during 10 days upon agroinfiltration (Ring et al., 2013). Importantly, the transcript levels of FaPOD remained unchanged after infection by Agrobacterium. In plants, a basal level of peroxidase functions probably as housekeeping activity in either elongation or lignification (Passardi et al., 2005). However, induction of POD activity in response to pathogen attack results in increased lignification (Xu et al., 2012) and thus reinforcement of plant cells to prevent the entry of pathogens. Similarly, FaPOD27 transcripts might be required to prevent the spreading of Agrobacterium in infected fruits. Elevated levels of $\mathrm{FaPOD} 27$ transcripts were detected in all strawberry fruits that were agroinfiltrated (Ring et al., 2013) and subsequently underwent active lignin synthesis (Figure 5BII). However, enzyme abundance and enzymatic activity of FaPOD27 was not determined in agroinfiltrated fruit.

It has also been reported that the expression of various isoenzymes is induced by different stress signals (Lauvergeat et al., 2001). Rice POX8.1 and POX22.3 were largely induced during resistant interactions, but POXgX9 was not induced by either wounding or pathogen (Chittoor et al., 1997). Similarly, FaPOD transcript levels remained unchanged although FaPOD27 transcription was strongly induced upon pathogen infection (Figure 3).

Agrobacterium-infected fruits, concomitant with induced FaPOD27 transcripts levels, clearly showed enhanced firmness and increased lignin content (Figures 4, 6). Likewise, PAL, CAD, and POD activities increased in loquat fruit, concurrently with the increase in lignin content (Cai et al., 2006). Moreover, the abundance of $F a C C R$ and $F a C A D$ transcripts in the mature fruit (Figure 2B) may supply sufficient monolignols that are oxidized by FaPOD27 to form additional lignin in Agrobacteriuminfected fruit. These results indicate that increased expression levels of FaPOD27 provoke the enhanced production of lignin in Agrobacterium-infected fruits. Thus, FaPOD27 is presumably a major factor involved in lignin biosynthesis associated with the defense response.

\section{PHENOTYPE, FRUIT FIRMNESS, AND LIGNIN CONTENT}

To demonstrate the role of monolignol genes in regulating lignin content in plants, monolignol genes were transiently 

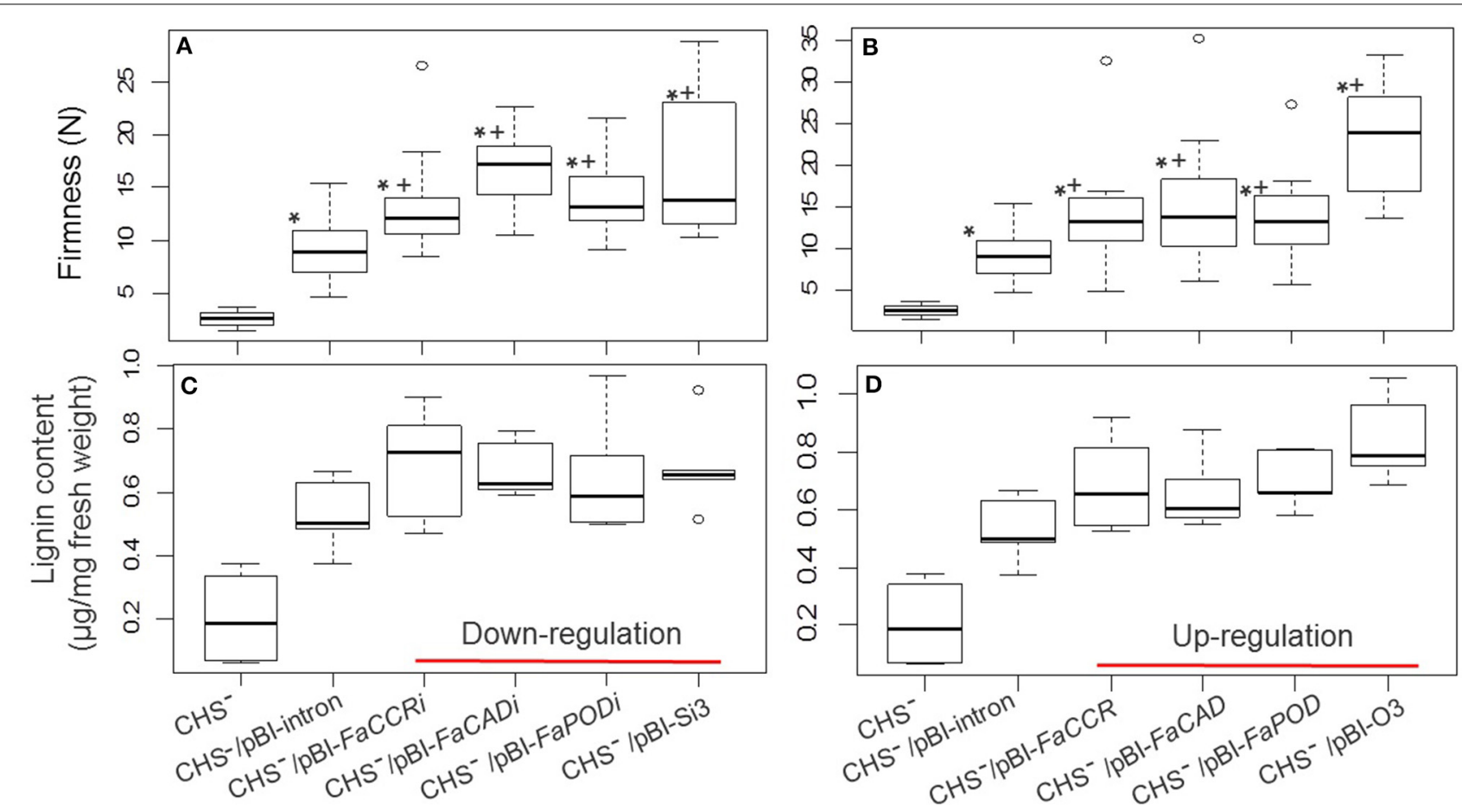

FIGURE 10 | Fruit firmness (A,B) and lignin content (C,D) of FaCCR-, FaCAD-, FaPOD-downregulation and -upregulation as well as combinations in $F \times$ ananassa cv. Calypso $\left(\mathrm{CHS}^{-}\right)$. (A) Firmness of Calypso ( $\left.\mathrm{CHS}^{-} ; n=15\right)$, control fruits $\left(\mathrm{CHS}^{-} / \mathrm{pBI}\right.$-intron; $n=17)$, down-regulated fruits ( $\mathrm{CHS}^{-} / \mathrm{pBI}-\mathrm{FaCCR} ; \quad n=14$,

$\left.\mathrm{CHS}^{-} / \mathrm{pBI}-\mathrm{FaCADi} ; n=14, \mathrm{CHS}^{-} / \mathrm{pBI}-\mathrm{FaPODi} ; n=17\right)$, and combined three genes $\left(\mathrm{CHS}^{-} / \mathrm{pBI}-\mathrm{Si} ; \quad n=15\right)$. (B) Firmness of Calypso $\left(\mathrm{CHS}^{-}\right.$, $n=15)$, control fruits $\left(\mathrm{CHS}^{-} / \mathrm{pBI}\right.$-intron; $\left.n=17\right)$, up-regulated fruits
( $\mathrm{CHS}^{-} / \mathrm{pBI}-\mathrm{FaCCR} ; n=14, \mathrm{CHS}^{-} / \mathrm{pBI}-\mathrm{FaCAD} ; n=17, \mathrm{CHS}^{-} / \mathrm{pBI}-\mathrm{FaPOD}$; $n=15)$, and combined three genes ( $\left.\mathrm{CHS}^{-} / \mathrm{pBI}-\mathrm{O} 3 ; n=18\right)$. (C,D) Lignin content of each group $(n=5)$. The Wilcoxon-Mann-Whitney $U$-test was used for non-parametric analysis of two groups. One asterisk $\left(^{*}\right)$ or a plus $(+)$ in the box marks statistically significant increased levels $(P<0.05)$ in comparison with $\mathrm{CHS}^{-}$and another group (indicated by ${ }^{*}$ ), or in comparison with $\mathrm{CHS}^{-} / \mathrm{pBI}$-intron and another group (indicated by + ). down-regulated by RNAi and over-expressed in strawberry fruits. In this study, the lignin content of agroinfiltrated fruits expressing down- and up-regulation constructs of monolignol genes equaled the level in the pBI-intron control fruits but was significantly higher than the content in untreated fruits (Figure 6). At the same time, all fruits exhibited normal growth and development (Figure 5BI). When monolignol genes are introduced into plants, transgenic plants show normal or unusual phenotypes, depending on the reduction in lignin content. An abnormal phenotype was observed when total lignin content decreased in CCR-down-regulated tobacco plants (Piquemal et al., 1998) but down-regulation of CAD did not significantly affect total lignin and tobacco plants exhibited a normal phenotype (Ralph et al., 1998). It was assumed that lignification was sufficiently plastic to enable CAD-down-regulated plants to form lignin from hydroxy cinnamylaldehydes (Humphreys and Chapple, 2002).

In addition, in our study, enhanced fruit firmness in agroinfiltrated fruits was always associated with increased lignin production, when compared to wild-type (untreated) fruits (Figure 6). This demonstrates a clear correlation between fruit firmness and lignin content. It has already been shown that lignification and lignin formation is induced by pathogen infection (Reimers and Leach, 1991; Passardi et al., 2005, 2006; Bhuiyan et al., 2009) which is a common behavior in a plant's defense against penetration by pathogens. In this work, lignin staining revealed lignin accumulation mainly in the vascular tissue in treated fruits exposed to Agrobacterium (Figure 5BII). It is assumed that deposition of lignin in agroinfiltrated fruits led to reinforced cell walls, resulting in enhanced firmness in the treated fruits.

\section{EFFECT OF TREATED FRUITS ON BIOSYNTHESIS OF PHENYLPROPANOID INTERMEDIATES}

Hydroxycinnamic acids accumulate exclusively as glucose ester in strawberry fruit but levels of the glucose ester may reflect the amounts of their corresponding phenylpropanoic acid precursors (Figure 1; Määttä-Riihinen et al., 2004). Increased levels of ferulic acid in wheat plants, exposed to bacterial infection, suggest the induction of a defense response to prevent bacterial infection in these plants (Parrott et al., 2002). Likewise reduced levels of $p$ coumaroyl glucoside/glucose and increased amounts of feruloyl and caffeoyl glucose ester were observed in agroinfiltrated fruits in comparison with untreated controls (Fig. S11), suggesting that coumaric acid is converted to fuel the lignin pathways.

In particular, the level of coumaric acid decreased in CCRdown-regulated lines of perennial ryegrass, whereas levels of caffeoylquinic acid, caffeoyl shikimic acid, ferulic acid, and sinapic acid increased in these transgenic plants ( $\mathrm{Tu}$ et al., 2010). In addition, low levels of CCR diverted $p$-coumaroyl-CoA into the 
synthesis of flavonoids, resulting in the accumulation of flavonol conjugates in CCR-deficient plants (van der Rest et al., 2006; $\mathrm{Tu}$ et al., 2010). Consistent with these result, FaCCR-silenced fruits contained the least amount of $p$-coumaroyl glucose esters (Fig. S11A). However, the levels of flavonol conjugates were not affected probably because most of the precursors of flavonols have been formed prior to agroinfiltration.

\section{RESTORATION OF LIGNIN CONTENT AND MODIFICATION OF MONOLIGNOL COMPOSITION}

Lignin content and composition play an important role in evaluating the results of genetic biotechnologies. Recent studies have shown that a compensatory mechanism occurs in CCR- and $C A D$-down-regulated angiosperms, in which elevated ferulic acid and hydroxyl cinnamaldehyde were incorporated into the lignin polymer (Lapierre et al., 1999; Chabannes et al., 2001; Ralph et al., 2008; Tu et al., 2010; Vanholme et al., 2010). It has been reported that both $p$-coumaric and ferulic acid were crosslinked to cell wall lignin of grasses (Grabber et al., 1991). In the present study, metabolite profiling detected increased levels of caffeic and ferulic acid glucose ester in strawberries injected with Agrobacterium (Fig. S11). Therefore, we assumed that elevated levels of ferulic and caffeic acid may be incorporated into lignin to restore its content in treated fruits. In recent years, thioacidolysis marker compounds for the incorporation of ferulic acid and hydroxy cinnamaldehyde into the lignin polymer have been established (Palmer et al., 2008; Ralph et al., 2008) and $\beta-\mathrm{O}-4$ coupled hydroxyl cinnamalaldehyde structures in lignin of CADdown-regulated tobacco have been revealed by NMR methods (Chabannes et al., 2001; Ralph et al., 2001). However, ferulic acid was not detected in significant amounts in treated strawberry fruits (Fig. S13) and the aldehyde was not seen in pBI-FaCADi lignin after thioacidolysis by GC-MS. Thus, the time period between agroinfiltration and harvest of the fruits is probably too short to incorporate greater amounts of ferulic acid or hydroxy cinnamaldehyde. Similarly, ferulic acid was also not detected in the $\mathrm{Zmccrl}^{-}$mutant (Tamasloukht et al., 2011). Remarkably, a new thioacidolysis product was detected in FaCCR-silenced fruits but remained unknown (Fig. S13).

In addition to reduced activities of target enzymes, CCR- and $C A D$-down-regulation in tobacco also affected the proportion of monolignols in the lignin polymer (Chabannes et al., 2001). In CCR-deficient plants such as tobacco, Arabidopsis, and maize the flux from feruloyl-CoA to $\mathrm{G}$ and $\mathrm{S}$ units is significantly decreased (Chabannes et al., 2001; Ralph et al., 2008; Tamasloukht et al., 2011). Similarly, we observed a significant reduction in the relative concentration of $\mathrm{G}$ units in $\mathrm{FaCCR}$-silenced fruits, as well as $\mathrm{G}$ and $\mathrm{S}$ units in pBI-FaCADi fruits compared with pBIintron control fruits (Table 2). In an in vitro study, GST-CCR was highly specific to feruloyl-CoA (Table 1) which nicely explains the decreased flux from feruloyl-CoA to G units in FaCCR $i$ fruits where the level of $C C R$ transcripts were significantly reduced (Figure 7A). Besides, the increase in the $S / G$ ratio of lignin in $\mathrm{FaCCR}$-silenced fruits was consistent with results obtained from CCR-deficient plants (Chabannes et al., 2001; Tamasloukht et al., 2011). It was showed that the recombinant FxaCAD1 (F. $\times$ ananassa cv. Chandler) enzyme is highly specific for coniferyl and sinapyl aldehydes in vitro (Blanco-Portales et al., 2002). This result is consistent with the observation of a decreased flux from coniferyl and sinapyl aldehyde to $\mathrm{G}$ and $\mathrm{S}$ units, respectively in $F a C A D$-silenced fruits. In addition, enhanced $F a P O D$ transcripts may not have a direct effect on total lignin content (Figures 6D, 7B), but levels of $G$ and $S$ units decreased significantly in pBIFaPOD fruits (Table 2). Hence, FaPOD seemed to be functional in a lignin related pathway in $F a P O D$-overexpressed fruit and is proposed as regulator of the lignin composition. Possible explanations are that FaPOD catalyzes a reaction that limits monolignol supply for lignin formation or inhibits the activity of other POD isoenzymes whereby regulating the proportion of $\mathrm{G}$ and $\mathrm{S}$ units in lignin. The results show that FaPOD activity is related with lignin composition probably in immature fruit where the gene is highly expressed (Figure 2B).

Altogether, variations in the $S$ to $G$ unit ratios of lignin may be attributed to the fact that different monolignol genes were introduced or silenced in the fruits (Table 2) whereas the overall lignin content in all treated fruits may be ascribed to elevated transcript levels of FaPOD27 (Figure 3). Elevated levels of FaPOD27 in agroinfiltrated fruits seem to have a much stronger effect on the total lignin content than down-regulation of lignin biosynthesis genes (Figure 7).

\section{INCREASED FIRMNESS AND LIGNIN LEVEL IN CHS- FRUITS DUE TO MANIPULATION OF MONOLIGNOL GENES}

Suppression of the CHS gene in strawberry fruit results in an increase in the pool of $p$-coumaroyl-CoA derived metabolites (Lunkenbein et al., 2006) which may serve as precursors for the synthesis of lignin through HCT and CCR activity (Figure 1). Similar to fruits of wild type F. $x$ ananassa cv Elsanta, in $\mathrm{CHS}^{-}$ fruits of F. $x$ ananassa cv. Calypso the increase in firmness upon agroinfiltration of different constructs was also associated with an increase in lignin content (Figure 10). A comparison revealed that fruits agroinfiltrated with silencing and overexpression constructs were firmer than $\mathrm{CHS}^{-} / \mathrm{pBI}$-intron control fruits (Figure 10).

It has been shown that flavonoid accumulation in $\mathrm{HCT}^{-}$ A. thaliana, repressed in lignin synthesis, affects auxin transport and plant growth (Besseau et al., 2007). Remarkably, auxin transport can be restored in $\mathrm{HCT}^{-} / \mathrm{CHS}^{-}$plants due to lower levels of flavonoids in the plants. Restoration of auxin transport also led to increased yields of lignin. In accordance with this model, $\mathrm{CHS}^{-}$ fruits contain lower levels of flavonoids than fruits of wild type F. $x$ ananassa cv. Calypso (Lunkenbein et al., 2006), resulting in increased lignin content in $\mathrm{CHS}^{-}$fruit upon agroinfiltration of different constructs in comparison with $\mathrm{CHS}^{-} / \mathrm{pBI}$-intron control (Figure 10). Besides, auxin affects growth of strawberries and early fruit development and delays ripening (Given et al., 1988) whereas fruit ripening is associated with rapid softening (Zhang et al., 2011). Thus, we assumed that increased auxin transport in $\mathrm{CHS}^{-}$fruits after agroinfiltration led to delayed ripening, which impacts on fruit firmness in addition of enhanced FaPOD27 expression induced by infection with Agrobacterium.

Although lignin provides structural support for all land plants, until recently, only carbohydrate polymers such as pectin and cellulose and to a lesser extent proteins such as the expansins have been regarded as structure forming and stabilizing components 
in fruits. Microarray analyses, however, have provided evidence that the expression of specific genes involved in lignin formation affect strawberry fruit firmness. In this study, the analyses of CCR, CAD, and POD genes from F. $x$ ananassa clearly revealed the significance of FaPOD27 for lignin formation and firmness in strawberry fruit. The gene does not only function in late stages of strawberry fruit ripening but is also a component of the fruit's defense mechanism against bacterial invasion. The results can be used to develop strawberry varieties with improved firmness, storage stability, enhanced resistance, and thus fruit quality.

\section{ACKNOWLEDGMENT}

We are grateful to Deutsche Forschungsgemeinschaft (DFG, Schw 634/1-1) for financial support.

\section{SUPPLEMENTARY MATERIAL}

The Supplementary Material for this article can be found online at: http://www.frontiersin.org/journal/10.3389/fpls.2014.00518/ abstract

\section{REFERENCES}

Almagro, L., Gómez Ros, L. V., Belchi-Navarro, S., Bru, R., Ros Barceló, A., and Pedreño, M. A. (2009). Class III peroxidases in plant defence reactions. J. Exp. Bot. 60, 377-390. doi: 10.1093/jxb/ern277

Anterola, A. M., and Lewis, N. G. (2002). Trends in lignin modification, a comprehensive analysis of the effects of genetic manipulations/mutations on lignification and vascular integrity. Phytochemistry 61, 221-294. doi: 10.1016/S0031-9422(02)00211-X

Besseau, S., Hoffmann, L., Geoffroy, P., Lapierre, C., Pollet, B., and Legrand, M. (2007). Flavonoid accumulation in Arabidopsis repressed in lignin synthesis affects auxin transport and plant growth. Plant Cell 19, 148-162. doi: 10.1105/tpc.106.044495

Beuerle, T., and Pichersky, E. (2002). Enzymatic synthesis and purification of aromatic coenzyme A esters. Anal. Biochem. 302, 305-312. doi: 10.1006/abio.2001.5574

Bhuiyan, N. H., Selvaraj, G., Wei, Y., and King, J. (2009). Gene expression profiling and silencing reveal that monolignol biosynthesis plays a critical role in penetration defence in wheat against powdery mildew invasion. J. Exp. Bot. 60, 509-521. doi: 10.1093/jxb/ern290

Blanco-Portales, R., Medina-Escobar, N., López-Ráez, J. A., González-Reyes, J. A., Villalba, J. M., Moyano, E., et al. (2002). Cloning, expression and immunolocalization pattern of a cinnamyl alcohol dehydrogenase gene from strawberry (Fragaria $\times$ ananassa cv. Chandler). J. Exp. Bot. 53, 1723-1734. doi: 10.1093/jxb/erf029

Boerjan, W., Ralph, J., and Baucher, M. (2003). Lignin biosynthesis. Ann. Rev. Plant Biol. 54, 519-546. doi: 10.1146/annurev.arplant.54.031902.134938

Bonello, P., and Blodgett, J. T. (2003). Pinus nigra-Sphaeropsis sapinea as a model pathosystem to investigate local and systemic effects of fungal infection of pines. Physiol. Mol. Plant Pathol. 63, 249-261. doi: 10.1016/j.pmpp.2004.02.002

Bourne, M. (2002). Food Texture and Viscosity, Concept and Measurement. Geneva; New York, London: Academic Press.

Cai, C., Xu, C. J., Li, X., Ferguson, I. B., and Chen, K. S. (2006). Accumulation of lignin in relation to change in activities of lignification enzymes in loquat fruit flesh after harvest. Postharv. Biol. Technol. 40, 163-169. doi: 10.1016/j.postharvbio.2005.12.009

Campbell, M. M., and Ellis, B. E. (1992). Fungal elicitor-mediated responses in pine cell cultures. I. Induction of phenylpropanoid metabolism. Planta 186, 409-417. doi: 10.1007/BF00195322

Carpin, S., Crevecoeur, M., de Meyer, M., Simon, P., Greppin, H., and Penel, C. (2001). Identification of a $\mathrm{Ca}^{2+}$-pectate binding site on an apoplastic peroxidase. Plant Cell 13, 511-520. doi: 10.1105/tpc.13.3.511

Chabannes, M., Barakate, A., Lapierre, C., Marita, J. M., Ralph, J., Pean, M., et al. (2001). Strong decrease in lignin content without significant alteration of plant development is induced by simultaneous down-regulation of cinnamoyl-CoA reductase (CCR) and cinnamyl alcohol dehydrogenase (CAD) in tobacco plants. Plant J. 28, 257-270. doi: 10.1046/j.1365-313X.2001.01140.x

Chapple, C., and Carpita, N. (1998). Plant cell walls as targets for biotechnology. Curr. Opin. Plant Biol. 1, 179-185. doi: 10.1016/S1369-5266(98)80022-8

Chittoor, M., Leach, J. E., and White, F. F. (1997). Differential induction of a peroxidase gene family during infection of rice by Xanthomonas oryzae pv. oryzae. Mol. Plant Microbe Interact. 10, 861-871. doi: 10.1094/MPMI.1997.10.7.861

Dixon, R. A. (2001). Natural products and disease resistance. Nature 411, 843-847. doi: $10.1038 / 35081178$

Dixon, R. A., Chen, F., Guo, D., and Parvathi, K. (2001). The biosynthesis of monolignols, a "metabolic grid," or independent pathways to guaiacyl and syringyl units? Phytochemistry 57, 1069-1084. doi: 10.1016/S0031-9422(01)00092-9

Dominguez-Puigjaner, E., Llop, I., Prats, S. A., and Vendrell, M. (1997). cDNA clone highly expressed in ripe banana fruit shows homology to pectates lyases. Plant Physiol. 114, 1071-1076. doi: 10.1104/pp.114.3.1071

Evtuguin, D. V., Neto, C. P., Silva, A. M., Domingues, P. M., Amado, F. M. L., Robert, D., et al. (2001). Comprehensive study on the chemical structure of dioxane lignin from plantation Eucalyptus globulus wood. J. Agric. Food Chem. 49, 4252-4261. doi: 10.1021/jf010315d

Franke, R., Hemm, M. R., Denault, J. W., Ruegger, M. O., Humphreys, J. M., and Chapple, C. (2002). Changes in secondary metabolism and deposition of an unusual lignin in the ref8 mutant of Arabidopsis. Plant J. 30, 47-59. doi: 10.1046/j.1365-313X.2002.01267.x

Given, N. K., Venis, M. A., and Grierson, D. (1988). Hormonal regulation of ripening in the strawberry, a non-climacteric fruit. Planta 174, 402-406. doi: 10.1007/BF00959527

Goffner, D., Campbell, M. M., Campargue, C., Clastre, M., Borderies, G., Boudet, A., et al. (1994). Purification and characterization of cinnamoyl-CoA,NADP oxidoreductase in Eucalyptus gunnii. Plant Physiol. 106, 625-632.

Grabber, J. H., Jung, G. A., and Hill, R. R. Jr. (1991). Chemical composition of parenchyma and sclerenchyma cell walls isolated from orchardgrass and switchgrass. Crop Sci. 31, 1058-1065. doi: 10.2135/cropsci1991.0011183X00 $3100040043 \mathrm{x}$

Hart, A. (2001). Mann-Whitney test is not just a test of medians, differences in spread can be important. British Med. J. 323, 391-393. doi: 10.1136/bmj.323.7309.391

Hayashi, T. (2006). The Science and Lore of the Plant Cell Wall. Boca Raton, FL: Brown Walker Press.

Hoffmann, T., Kalinowski, G., and Schwab, W. (2006). RNAi-induced silencing of gene expression in strawberry fruit (Fragaria $\times$ ananassa) by agroinfiltration. A rapid assay for gene function analysis. Plant J. 48, 818-826. doi: 10.1111/j.1365313X.2006.02913.x

Humphreys, J. M., and Chapple, C. (2002). Rewriting the lignin roadmap. Curr. Opin. Plant Biol. 5, 224-229. doi: 10.1016/S1369-5266(02)00257-1

Hushpulian, D. M., Savitski, P. A., Rojkova, A. M., Chubar, T. A., Fechina, V. A., Sakharov, I. Y. U., et al. (2003). Expression and refolding of tobacco anionic peroxidase from E. coli inclusion bodies. Biochemistry (Moscow) 68, 1189-1194. doi: 10.1023/B:BIRY.0000009132.45842.93

Jiménez-Bermúdez, S., Redondo-Nevado, J., Muñoz-Blanco, J., Caballero, J. L., López- Aranda, J. M., Valpuesta, V., et al. (2002). Manipulation of strawberry fruit softening by antisense expression of a pectate lyase gene. Plant Physiol. 128, 751-759. doi: 10.1104/pp.010671

Kim, S. J., Kim, M. R., Bedgar, D. L., Moinuddin, S. G., Cardenas, C. L., Davin, L. B., et al. (2004). Functional reclassification of the putative cinnamyl alcohol dehydrogenase multigene family in Arabidopsis. Proc. Natl. Acad. Sci. U.S.A. 101, 1455-1460. doi: 10.1073/pnas.0307987100

Lacombe, E., Hawkins, S., Van Doorsselaere, J., Piquemal, J., Goffner, D., Poeydomenge, O., et al. (1997). Cinnamoyl CoA reductase, the first committed enzyme of the lignin branch biosynthetic pathway, cloning, expression and phylogenetic relationships. Plant J. 11, 429-441. doi: 10.1046/j.1365313X.1997.11030429.x

Lapierre, C., Pollet, B., Petit-Conil, M., Toval, G., Romero, J., Pilate, G., et al. (1999). Structural alterations of lignins in transgenic poplars with depressed cinnamyl alcohol dehydrogenase or caffeic acid $O$-methyltransferase activity have an opposite impact on the efficiency of industrial kraft pulping. Plant Phys. 119, 153-163. doi: 10.1104/pp.119.1.153

Lauvergeat, V., Lacomme, C., Lacombe, E., Lasserre, E., Roby, D., and GrimaPettenati, J. (2001). Two cinnamoyl-CoA reductase (CCR) genes from Arabidopsis thaliana are differentially expressed during development and in 
response to infection with pathogenic bacteria. Phytochemistry 57, 1187-1195. doi: 10.1016/S0031-9422(01)00053-X

Lazo, G. R., Pascal, A. S., and Ludwig, R. A. (1991). A DNA transformationcompetent Arabidopsis genomic library in Agrobacterium. Biotechnology 9, 963-967. doi: 10.1038/nbt1091-963

Lefever, G., Vieuille, M., Delage, N., D'Harlingue, A., de Monteclerc, J., and Bompeix, G. (2004). Characterization of cell wall enzyme activities, pectin composition, and technological criteria of strawberry cultivars (Fragaria $\times$ ananassa Duch). J. Food Sci. 69, 221-226. doi: 10.1111/j.1365-2621.2004.tb06320.x

Li, L., Cheng, X. F., Leshkevich, J., Umezawa, T., Harding, S. A., and Chiang, V. L. (2001). The last step of syringyl monolignol biosynthesis in angiosperms is regulated by a novel gene encoding sinapyl alcohol dehydrogenase. Plant Cell 13, 1567-1585. doi: 10.1105/tpc.13.7.1567

Li, L., Cheng, X., Lu, S., Nakatsubo, T., Umezawa, T., and Chiang, V. L. (2005). Clarification of cinnamoyl co-enzyme A reductase catalysis in monolignol biosynthesis of Aspen. Plant Cell Physiol. 46, 1073-1082. doi: 10.1093/pcp/ pcil 20

Liao, Z., Chen, M., Guo, L., Gong, Y., Tang, F., Sun, X., et al. (2004). Rapid isolation of high-quality total RNA from Taxus and Ginkgo. Prep. Biochem. Biotechnol. 34, 209-214. doi: 10.1081/PB-200026790

Liu, G., Sheng, X., Greenshields, D. L., Ogieglo, A., Kaminskyj, S., Selvaraj, G., et al. (2005). Profiling of wheat class III peroxidase genes derived from powdery mildew-attacked epidermis reveals distinct sequence-associated expression patterns. Mol. Plant Microbe Interact. 18, 730-741. doi: 10.1094/MPMI18-0730

Livak, K. J., and Schmittgen, T. D. (2001). Analysis of relative gene expression data using real-time quantitative PCR and the $2^{-\Delta \Delta C T}$ method. Methods 25, 402-408. doi: 10.1006/meth.2001.1262

Lunkenbein, S., Coiner, H., de Vos, C. H., Schaart, J. G., Boone, M. J., Krens, F. A., et al. (2006). Molecular characterization of a stable antisense chalcone synthase phenotype in strawberry (Fragaria $x$ ananassa). J. Agri. Food Chem. 54, 2145-2153. doi: 10.1021/jf052574z

Määttä-Riihinen, K. R., Kamal-Eldin, A., and Törrönen, A. R. (2004). Identification and quantification of phenolic compounds in berries of Fragaria and Rubus species (family Rosaceae). J. Agric. Food Chem. 52, 6178-6187. doi: 10.1021/jf049450r

Manning, K. (1998). Genes for Fruit Quality in Strawberry. Wallingford: CAB International.

Medina-Escobar, N., Cárdenas, J., Moyano, E., Caballero, J. L., and Muñoz-Blanco, J. (1997). Cloning, molecular characterization and expression pattern of a strawberry ripening-specific cDNA with sequence homology to pectate lyase from higher plants. Plant Mol. Biol. 34, 867-877.

Meyer, K., Shirley, A. M., Cusumano, J. C., Bell-Lelong, D. A., and Chapple, C. (1998). Lignin monomer composition is determined by the expression of a cytochrome P450-dependent monooxygenase in Arabidopsis. Proc. Natl. Acad. Sci. U.S.A. 95, 6619-6623. doi: 10.1073/pnas.95.12.6619

Moura, J. C. M. S., Bonine, C. A. V., Viana, J. O. F., Dornelas, M. C., and Mazzafera, P. (2010). Abiotic and biotic stresses and changes in the lignin content and composition in plants. J. Integr. Plant Biol. 52, 360-376. doi: 10.1111/j.1744-7909.2010.00892.x

Palmer, N. A., Sattler, S. E., Saathoff, A. J., Funnell, D., Pedersen, J. F., and Sarath, G. (2008). Genetic background impacts soluble and cell wall-bound aromatics in brown midrib mutants of sorghum. Planta 229, 115-127. doi: 10.1007/s00425008-0814-1

Parrott, D. L., Anderson, A. J., and Carman, J. G. (2002). Agrobacterium induces plant cell death in wheat (Triticum aestivum L.). Physiol. Mol. Plant Pathol. 60, 59-69. doi: 10.1006/pmpp.2002.0378

Passardi, F., Cosio, C., Penel, C., and Dunand, C. (2005). Peroxidases have more functions than a Swiss army knife. Plant Cell Rep. 24, 255-265. doi: 10.1007/s00299-005-0972-6

Passardi, F., Longet, D., Penel, C., and Dunand, C. (2004a). The class III peroxidase multigenic family in rice and its evolution in land plants. Phytochemistry 65, 1879-1893. doi: 10.1016/j.phytochem.2004.06.023

Passardi, F., Penel, C., and Dunand, C. (2004b). Performing the paradoxical, how plant peroxidases modify the cell wall. Trends Plant Sci. 9, 534-540. doi: 10.1016/j.tplants.2004.09.002

Passardi, F., Tognolli, M., de Meyer, M., Penel, C., and Dunand, C. (2006). Two cell wall associated peroxidases from Arabidopsis influence root elongation. Planta 223, 965-974. doi: 10.1007/s00425-005-0153-4
Pichon, M., Courbou, I., Beckert, M., Boudet, A. M., and Grima-Pettenati, J. (1998). Cloning and characterization of two maize cDNAs encoding cinnamoylCoA reductase (CCR) and differential expression of the corresponding genes. Plant Mol. Biol. 38, 671-676. doi: 10.1023/A:1006060101866

Piquemal, J., Lapierre, C., Myton, K., O’Connell, A., Schuch, W., Grima-Pettenati, J., et al. (1998). Down-regulation of cinnamoyl-CoA reductase induces significant changes of lignin profiles in transgenic tobacco plants. Plant J. 13, 71-83.

Quesada, M. A., Blanco-Portales, R., Posé, S., García-Gago, J. A., JiménezBermúdez, S., Muñoz-Serrano, A., et al. (2009). Antisense down-regulation of the FaPG1 gene reveals an unexpected central role for polygalacturonase in strawberry fruit softening. Plant Physiol. 150, 1022-1032. doi: 10.1104/pp.109.138297

Raab, T., López-Ráez, J. A., Klein, D., Caballero, J. L., Moyano, E., Schwab, W., et al. (2006). FaQR, required for the biosynthesis of the strawberry flavor compound 4-hydroxy-2,5-dimethyl-3(2H)-furanone, encodes an enone oxidoreductase. Plant Cell 18, 1023-1037. doi: 10.1105/tpc.105.039784

Ralph, J., Hatfield, R. D., Piquemal, J., Yahiaoui, N., Pean, M., Lapierre, C., et al. (1998). NMR characterization of altered lignins extracted from tobacco plants down-regulated for lignification enzymes cinnamyl alcohol dehydrogenase and cinnamoyl-CoA reductase. Proc. Natl. Acad. Sci. U.S.A. 95, 12803-12808. doi: 10.1073/pnas.95.22.12803

Ralph, J., Kim, H., Lu, F., Grabber, J. H., Leple, J. C., Berrio-Sierra, J., et al. (2008). Identification of the structure and origin of a thioacidolysis marker compound for ferulic acid incorporation into angiosperm lignins (and an indicator for cinnamoyl CoA reductase deficiency). Plant J. 53, 368-379. doi: 10.1111/j.1365-313X.2007.03345.x

Ralph, J., Lapierre, C., Marita, J. M., Kim, H., Lu, F., Hatfield, R. D., et al. (2001). Elucidation of new structures in lignins of CAD- and COMT-deficient plants by NMR. Phytochemistry 57, 993-1003. doi: 10.1016/S0031-9422(01)00109-1

Reimers, P. J., and Leach, J. E. (1991). Race-specific resistance to Xanthomonas oryzae pv. oryzae conferred by bacterial blight resistance gene Xa-10 in rice (Oryza sativa) involves accumulation of a lignin-like substance in host tissues. Physiol. Mol. Plant Pathol. 38, 39-55. doi: 10.1016/S0885-5765(05)80141-9

Ring, L., Yeh, S. Y., Hücherig, S., Hoffmann, T., Blanco-Portales, R., Fouche, M., et al. (2013). Metabolic interaction between anthocyanin and lignin biosynthesis is associated with peroxidase FaPRX27 in strawberry fruit. Plant Physiol. 163, 43-60. doi: 10.1104/pp.113.222778

Robinson, A. R., and Mansfield, S. D. (2009). Rapid analysis of poplar lignin monomer composition by a streamlined thioacidolysis procedure and nearinfrared reflectance-based prediction modeling. Plant J. 58, 706-714. doi: 10.1111/j.1365-313X.2009.03808.x

Rushton, P. J., and Somssich, I. E. (1998). Transcriptional control of plant genes responsive to pathogens. Curr. Opin. Plant Biol. 1, 311-315. doi: 10.1016/13695266(88)80052-9

Salentijn, E. M. J., Aharoni, A., Schaart, J. G., Boone, M. J., and Krens, F. A. (2003). Differential gene expression analysis of strawberry cultivars that differ in fruit-firmness. Physiol. Planta. 118, 571-578. doi: 10.1034/j.1399-3054.2003. 00138.x

Sarni, F., Grand, C., and Boudet, A. M. (1984). Purification and properties of cinnamoyl-CoA reductase and cinnamyl alcohol dehydrogenase from poplar stems (Populus $\times$ eurarnericana). Eur. J. Biochem. 139, 259-265. doi: 10.1111/j.1432-1033.1984.tb08002.x

Schwab, W., Hoffmann, T., Kalinowski, G., and Preuß, A. (2011). Functional genomics in strawberry fruit through RNAi-mediated silencing. Genes Genomes Genomics 5, 91-101.

Seymour, G. B., and Gross, K. C. (1996). Cell wall disassembly and fruit softening. Postharv. News Info. 7, 45N-52N.

Singh, K. K., and Reddy, B. S. (2006). Post-harvest physico-mechanical properties of orange peel and fruit. J. Food Eng. 73, 112-120. doi: 10.1016/j.jfoodeng.2005. 01.010

Tamasloukht, B., Wong Quai Lam, M. S., Martinez, Y., Tozo, K., Barbier, O., Jourda, C., et al. (2011). Characterization of a cinnamoyl-CoA reductase 1 (CCR1) mutant in maize, effects on lignification, fibre development, and global gene expression. J. Exp. Bot. 62, 3837-3848. doi: 10.1093/jxb/err077

Tu, Y., Rochfort, S., Liu, Z., Ran, Y., Griffith, M., Badenhorst, P., et al. (2010) Functional analyses of caffeic acid O-methyltransferase and cinnamoyl-CoAreductase genes from perennial ryegrass (Lolium perenne). Plant Cell 22, 3357-3373. doi: 10.1105/tpc.109.072827 
van der Rest, B., Danoun, S., Boudet, A. M., and Rochange, S. F. (2006). Downregulation of cinnamoyl-CoA reductase in tomato (Solanum lycopersicum L.) induces dramatic changes in soluble phenolic pools. J. Exp. Bot. 57, 1399-1411. doi: $10.1093 /$ jxb/erj120

Vanholme, R., Demedts, B., Morreel, K., Ralph, J., and Boerjan, W. (2010). Lignin biosynthesis and structure. Plant Physiol. 153, 895-905. doi: 10.1104/pp.110.155119

Ward, G., Hadar, Y., Bilkis, I., Konstantinovsky, L., and Dosoretz, C. G. (2001). Initial steps of ferulic acid polymerization by lignin peroxidase. J. Biol. Chem. 276, 18734-18741. doi: 10.1074/jbc.M009785200

Welinder, K. G., Justesen, A. F., Kjaersgård, I. V., Jensen, R. B., Rasmussen, S. K., Jespersen, H. M., et al. (2002). Structural diversity and transcription of class III peroxidases from Arabidopsis thaliana. Eur. J. Biochem. 269, 6063-6081. doi: 10.1046/j.1432-1033.2002.03311.x

Weng, J.-K., and Chapple, C. (2010). The origin and evolution of lignin biosynthesis. New Phytol. 187, 273-285. doi: 10.1111/j.1469-8137.2010.03327.x

Wengenmayer, H., Ebel, J., and Grisebach, H. (1976). Enzymic synthesis of lignin precursors, purification and properties of a cinnamoyl-CoA, NADPH reductase from cell suspension cultures of soybean (Glycine max). Eur. J. Biochem. 65, 529-536. doi: 10.1111/j.1432-1033.1976.tb10370.x

Whetten, R. W., MacKay, J. J., and Sederoff, R. R. (1998). Recent advances in understanding lignin biosynthesis. Ann. Rev. Plant Physiol. Plant Mol. Biol. 49, 585-609. doi: 10.1146/annurev.arplant.49.1.585

Xu, L., Zhu, L., Tu, L., Liu, L., Yuan, D., Jin, L., et al. (2012). Lignin metabolism has a central role in the resistance of cotton to the wilt fungus Verticillium dahliae as revealed by RNA-Seq-dependent transcriptional analysis and histochemistry. J. Exp. Bot. 62, 5607-5621. doi: 10.1093/jxb/err245

Zhang, J., Wang, X., Yu, O., Tang, J., Gu, X., Wan, X., et al. (2011). Metabolic profiling of strawberry (Fragaria $\times$ ananassa Duch.) during fruit development and maturation. J. Exp. Bot. 62, 1103-1118. doi: 10.1093/jxb/ erq343

Conflict of Interest Statement: The authors declare that the research was conducted in the absence of any commercial or financial relationships that could be construed as a potential conflict of interest.

Received: 05 August 2014; accepted: 15 September 2014; published online: 09 October 2014.

Citation: Yeh S-Y, Huang F-C, Hoffmann T, Mayershofer M and Schwab W (2014) FaPOD27 functions in the metabolism of polyphenols in strawberry fruit (Fragaria sp.). Front. Plant Sci. 5:518. doi: 10.3389/fpls.2014.00518

This article was submitted to Plant Metabolism and Chemodiversity, a section of the journal Frontiers in Plant Science.

Copyright (c) 2014 Yeh, Huang, Hoffmann, Mayershofer and Schwab. This is an open-access article distributed under the terms of the Creative Commons Attribution License (CC BY). The use, distribution or reproduction in other forums is permitted, provided the original author(s) or licensor are credited and that the original publication in this journal is cited, in accordance with accepted academic practice. No use, distribution or reproduction is permitted which does not comply with these terms. 